\title{
An Investigation of the Ocean's Role in Atlantic Multidecadal Variability
}

\author{
LAIFANG LI ${ }^{\mathrm{a}, \mathrm{b}}$ AND M. SUSAN LOZIER ${ }^{\mathrm{c}}$ \\ Earth and Ocean Sciences, Nicholas School of the Environment, Duke University, Durham, North Carolina \\ MARTHA W. BUCKLEY \\ George Mason University, Fairfax, Virginia
}

(Manuscript received 27 March 2019, in final form 8 January 2020)

\begin{abstract}
A mechanistic understanding of the Atlantic multidecadal variability (AMV) is highly desirable since it will considerably aid regional and global climate predictions. Although ocean dynamics have long been invoked to explain the AMV, recent studies have cast doubt on its influence. Here we evaluate the necessity of ocean dynamics for the AMV using an observationally based idealized model that isolates the contribution of atmospheric forcing to the AMV. By demonstrating that this model underestimates the magnitude of the observed sea surface temperature variability in the extratropical North Atlantic, we infer that ocean dynamics contribute significantly to the AMV in this region. This inference holds when we add anthropogenic aerosol forcing and the effects of mixed layer depth variability to the idealized model. Thus, our study suggests that ocean heat transport convergence is needed to explain sea surface temperature variability in the extratropical North Atlantic. Sustained ocean observing systems in the this region will help untangle the physical mechanisms involved.
\end{abstract}

\section{Introduction}

The Atlantic multidecadal variability (AMV) is a mode of basinwide sea surface temperature (SST) variability over the North Atlantic Ocean with pronounced signals at decadal-to-multidecadal time scales (Schlesinger and Ramankutty 1994; Kerr 2000). The AMV significantly affects global and regional climate [see review by Zhang et al. (2019)] through its impact on the global-mean temperature (Ting et al. 2009), the position of the Atlantic intertropical convergence zone (Ting et al. 2011), the North Atlantic jet stream and storm-track locations (Häkkinen et al. 2011; Woollings et al. 2012), climate over North America and western Europe (Enfield et al. 2001; Hoerling and Kumar 2003; McCabe et al. 2004; Sutton and Hodson 2005; O'Reilly et al.

\footnotetext{
${ }^{\text {a }}$ ORCID: 0000-0002-6721-9002.

${ }^{\mathrm{b}}$ Current affiliation: Department of Meteorology and Atmospheric Science, the Pennsylvania State University, University Park, Pennsylvania.

${ }^{\mathrm{c}}$ Current affiliation: School of Earth and Atmospheric Sciences, Georgia Institute of Technology, Atlanta, Georgia.
}

Corresponding author: Laifang Li, laifang.li@duke.edu; 1f15240@ psu.edu
2017), monsoon precipitation over the African Sahel (Zhang and Delworth 2006; Shanahan et al. 2009), and North Atlantic hurricanes (Goldenberg et al. 2001; Trenberth and Shea 2006). Thus, the importance of understanding what drives the AMV cannot be overstated.

Many past studies have explored AMV driving mechanisms. On the one hand, studies based on simulations using fully coupled models suggest a strong relationship between the AMV and the Atlantic meridional overturning circulation (AMOC). In these studies, the warm phase of the AMV is correlated with an intensified AMOC that acts to increase the ocean's northward heat transport (Delworth et al. 1993; Timmermann et al. 1998; Latif and Keenlyside 2011; Ruprich-Robert and Cassou 2015; Delworth et al. 2017; Zhang 2017; Zhang et al. 2019). A prominent role for ocean dynamics is evident in forcing the AMV SST anomaly (SSTA) and setting its periodicity (Drews and Greatbatch 2017; Kim et al. 2018; Zhang et al. 2019). On the other hand, a recent study (Clement et al. 2015) has shown that an atmospheric model coupled to a slab ocean produces an AMV similar to that of fully coupled models and in the observational record. This study concludes that atmospheric forcing alone is sufficient to generate the AMV. 
Observational evidence in support of either of these contrasting model-based views is limited. One study uses century-long sea level data along the U.S. East Coast to show that ocean currents modulate subpolar North Atlantic heat content, adding support to the contention of the ocean as a strong contributor to the AMV (McCarthy et al. 2015). A few other studies have demonstrated that on multidecadal time scales positive (negative) SSTA are related to turbulent heat fluxes out of (into) the ocean (Gulev et al. 2013), a linkage that has been interpreted as an indication of the ocean driving the AMV (Cayan 1992; Drews and Greatbatch 2016; O'Reilly et al. 2016; Zhang et al. 2016). Collectively, these studies support the "ocean" view; however, it has recently been demonstrated that this positive linkage may instead be an artifact of smoothing methods (Cane et al. 2017); uncertainties remain regarding the impact that oceanic damping has on the linkage (Zhang 2017).

Thus, no consensus has emerged to date on the role of the ocean in driving the AMV (Sutton et al. 2018). In large part, this impasse is attributable to the paucity of ocean observations in time and space. Sidestepping this hurdle, we utilize the ample atmospheric observational record, as well as SST observations, to assess the degree to which atmospheric variability alone can account for the AMV. Specifically, we infer the role of the ocean by comparing the SSTA produced from an idealized red-noise model, built to mimic an atmosphere-only forced ocean mixed layer, to the observed SSTA. We interpret any mismatch as an implication that ocean dynamics is a driver of North Atlantic SST variability.

\section{Data and methods}

In this section we derive our conceptual red-noise model from the mixed layer heat budget. We then outline the observational datasets used to derive the parameters of our model.

\section{a. Conceptualize mixed layer heat balance as a red-noise model}

The starting point for the derivation of our conceptual red-noise model is the mixed layer heat budget. In the equations and formulations below, overbars denote the climatological monthly mean of a variable. Primes are the deviation from the monthly climatology, and the resultant anomaly is also detrended. The SSTA tendency in the mixed layer, which results from the net exchange of heat across the air-sea interface and heat fluxes due to oceanic processes, is formulated as

$$
\frac{\partial T^{\prime}}{\partial t}=\left[\frac{Q_{\mathrm{net}}}{\left(\rho_{o} C_{p}^{o} h_{m}\right)}\right]^{\prime}+H_{\mathrm{ocean}}^{\prime},
$$

where $T^{\prime}$ is the SSTA, $Q_{\text {net }}$ is the net surface heat flux into the ocean (positive downward), $h_{m}$ is the ocean mixed layer depth (MLD), $H_{\text {ocean }}^{\prime}$ is the anomalous heat convergence due to oceanic processes (i.e., the sum of the convergence of horizontal and vertical heat flux by large-scale circulation and eddies, entrainment, and diffusive heat flux at the base of the mixed layer), $\rho_{o}=1024 \mathrm{~kg} \mathrm{~m}^{-3}$ is the reference density, and $C_{p}^{o}=$ $3850 \mathrm{~J} \mathrm{~kg}^{-1} \mathrm{~K}^{-1}$ is the specific heat of seawater.

The term $\left[Q_{\text {net }} /\left(\rho_{o} C_{p}^{o} h_{m}\right)\right]^{\prime}$ includes both net surface heat flux anomalies $Q_{\text {net }}^{\prime}$ and MLD anomalies $h_{m}^{\prime}$, i.e., $\left[Q_{\text {net }} /\left(\rho_{o} C_{p}^{o} h_{m}\right)\right]^{\prime}=\left[1 /\left(\rho_{o} C_{p}^{o}\right)\right]\left[\left(Q_{\text {net }}^{\prime} / \overline{h_{m}}\right)+\right.$ $\left.\overline{Q_{\text {net }}}\left(1 / h_{m}\right)^{\prime}\right]$. Expanding the term $\left(1 / h_{m}\right)^{\prime}$ and linearizing about the monthly climatology of MLD based on Taylor expansion yields $\left[Q_{\text {net }} /\left(\rho_{o} C_{p}^{o} h_{m}\right)\right]^{\prime}=Q_{\text {net }}^{\prime} /\left(\rho_{o} C_{p}^{o} \bar{h}_{m}\right)-$ $\overline{Q_{\text {net }}} h_{m}^{\prime} /\left[\rho_{o} C_{p}^{o}\left(\bar{h}_{m}\right)^{2}\right]$. With the above expansion of $\left[Q_{\text {net }} /\left(\rho_{o} C_{p}^{o} h_{m}\right)\right]^{\prime}$, Eq. (1) can be expressed as

$$
\frac{\partial T^{\prime}}{\partial t}=\frac{Q_{\text {net }}^{\prime}}{\rho_{o} C_{p}^{o} \bar{h}_{m}}-\frac{\overline{Q_{\text {net }}} h_{m}^{\prime}}{\rho_{o} C_{p}^{o}\left(\bar{h}_{m}\right)^{2}}+H_{\text {ocean }}^{\prime} .
$$

Here, $Q_{\text {net }}^{\prime}$ consists of four terms: downward solar radiation absorbed by the mixed layer (i.e., downward solar radiation at the surface minus the penetration of solar radiation at the bottom of the mixed layer), longwave radiation back to the atmosphere, and turbulent sensible and latent heat fluxes (i.e., $Q_{\mathrm{net}}^{\prime}=Q_{\mathrm{SW}}^{\prime}-Q_{\mathrm{LW}}^{\prime}-Q_{\mathrm{SH}}^{\prime}-$ $\left.Q_{\mathrm{LH}}^{\prime}\right)$. Bulk formulas relate the turbulent heat fluxes to surface wind speed $|U|$, the air-sea temperature difference $\left(T-T_{a}\right)$, and the air-sea humidity difference $\left(q-q_{a}\right)$ as

$$
\begin{aligned}
& Q_{\mathrm{SH}}=\rho_{a} C_{D}|U| C_{p}^{a}\left(T-T_{a}\right), \\
& Q_{\mathrm{LH}}=\rho_{a} C_{D}|U| L_{v}\left(q-q_{a}\right) .
\end{aligned}
$$

In Eqs. (3) and (4), $\rho_{a}=1.225 \mathrm{~kg} \mathrm{~m}^{-3}$ is the density of air, $C_{D}=1.15 \times 10^{-3}$ is the transfer coefficient for sensible and latent heat, $C_{p}^{a}=1004 \mathrm{~J} \mathrm{~kg}^{-1} \mathrm{~K}^{-1}$ is the specific heat of air, and $L_{v}=2.5 \times 10^{6} \mathrm{~J} \mathrm{~kg}^{-1}$ is the latent heat of vaporization.

Neglecting second-order terms, the turbulent heat flux anomalies can be quantified as

$$
\begin{aligned}
Q_{\mathrm{SH}}^{\prime} & =\rho_{a} C_{D} C_{p}^{a}\left[\overline{|U|}\left(T^{\prime}-T_{a}^{\prime}\right)+|U|^{\prime}\left(\bar{T}-\bar{T}_{a}\right)\right], \\
Q_{\mathrm{LH}}^{\prime} & =\rho_{a} C_{D} L_{v}\left[\overline{|U|}\left(q^{\prime}-q_{a}^{\prime}\right)+|U|^{\prime}\left(\bar{q}-\bar{q}_{a}\right)\right] .
\end{aligned}
$$

Since the atmosphere near the ocean surface is saturated, and the saturation humidity is a function of temperature, 
$q^{\prime}$ is determined solely by $T^{\prime}$ and is thus formulated as $q^{\prime}=\left.L_{v}(\partial q / \partial T)\right|_{T} T^{\prime}$. Given the dependence of $q^{\prime}$ on $T^{\prime}$, Eq. (6) can be expressed as

$$
Q_{\mathrm{LH}}^{\prime}=\rho_{a} C_{D} L_{v}\left\{\overline{|U|}\left[\left.\frac{\partial q}{\partial T}\right|_{\bar{T}} T^{\prime}-q_{a}^{\prime}\right]+|U|^{\prime}\left(\bar{q}-\bar{q}_{a}\right)\right\} .
$$

As can be seen from Eqs. (5) and (7), anomalies in the surface sensible and latent heat fluxes are a function of SSTA $\left(T^{\prime}\right)$ and atmospheric variables. Anomalies in the atmospheric variables $\left(|U|^{\prime}, T_{a}^{\prime}\right.$, and $\left.q_{a}^{\prime}\right)$ may result from internal atmospheric variability or be the response to the underlying SSTA. To quantify the response of the atmospheric variables to SSTA, we separate the turbulent heat flux anomalies into two components: anomalies due to SSTA (we assume a linear relationship) and a residual that contains the atmospheric contribution. With this separation, Eqs. (5) and (7) are expressed as

$$
\begin{aligned}
Q_{\mathrm{SH}}^{\prime}= & \rho_{a} C_{D} C_{p}^{a}\left[\overline{|U|}\left(T^{\prime}-\frac{\partial T_{a}}{\partial T} T^{\prime}\right)+\frac{\partial|U|}{\partial T} T^{\prime}\left(\bar{T}-\bar{T}_{a}\right)\right] \\
& +Q_{\mathrm{SH} \_ \text {res }}^{\prime}, \\
Q_{\mathrm{LH}}^{\prime}= & \rho_{a} C_{D} L_{v}\left[\overline{|U|}\left(\left.\frac{\partial q}{\partial T}\right|_{\bar{T}} T^{\prime}-\frac{\partial q_{a}}{\partial T} T^{\prime}\right)\right. \\
& \left.+\frac{\partial|U|}{\partial T} T^{\prime}\left(\bar{q}-\bar{q}_{a}\right)\right]+Q_{\mathrm{LH} \_ \text {res }}^{\prime} .
\end{aligned}
$$

In Eqs. (8) and (9), $Q_{\mathrm{SH} \_ \text {res }}^{\prime}$ and $Q_{\mathrm{LH} \_ \text {res }}^{\prime}$ are the residuals of the sensible heat flux and latent heat flux, respectively. Adding Eqs. (8) and (9), the turbulent heat flux anomalies are quantified as

$$
\begin{aligned}
Q_{\mathrm{SH}}^{\prime}+Q_{\mathrm{LH}}^{\prime}= & \{\underbrace{\rho_{a} C_{D} \overline{|U|}\left(C_{p}^{a}+\left.L_{v} \frac{\partial q}{\partial T}\right|_{\bar{T}}\right)}_{\alpha_{\text {self }}}+\underbrace{\rho_{a} C_{D}\left[C_{p}^{a}\left(\bar{T}-\overline{T_{a}}\right)+L_{v}\left(\bar{q}-\bar{q}_{a}\right)\right] \frac{\partial|U|}{\partial T}}_{\alpha_{|U|}} \\
& \underbrace{-\rho_{a} C_{D} \overline{|U|}\left(C_{p}^{a} \frac{\partial T_{a}}{\partial T}+L_{v} \frac{\partial q_{a}}{\partial T}\right)}_{\alpha_{\text {thermal }}}\} T^{\prime}+Q_{\text {SH_res }_{\text {res }}}^{\prime}+Q_{\mathrm{LH}_{\_} \text {res }}^{\prime} .
\end{aligned}
$$

The dependence of turbulent heat flux on SSTA [term in brackets on the right-hand side of Eq. (10)] provides an important SSTA damping mechanism (Stephens et al. 2012), whose intensity can be quantified by a damping coefficient, $\alpha$. Terms that involve $T^{\prime}$ in Eq. (10) decompose $\alpha$ into three components: a direct response of sensible and latent heat flux to SSTA $\left(\alpha_{\text {self }}\right)$, the response of wind speed to SSTA $\left(\alpha_{|U|}\right)$, and the thermal adjustment of air temperature and humidity to SSTA $\left(\alpha_{\text {thermal }}\right)$ :

$$
\alpha=\alpha_{\text {self }}+\alpha_{|U|}+\alpha_{\text {thermal }} .
$$

The term $\alpha_{\text {self }}=\rho_{a} C_{D} \overline{|U|}\left[C_{p}^{a}+\left.L_{v}(\partial q / \partial T)\right|_{T}\right]$ is determined by the background wind speed $\overline{|U|}$ and the sensitivity of saturation specific humidity to SSTA, which increases exponentially with background SST. The terms $\alpha_{|U|}=\rho_{a} C_{D}\left[C_{p}^{a}\left(\bar{T}-\bar{T}_{a}\right)+L_{v}\left(\bar{q}-\bar{q}_{a}\right)\right](\partial|U| / \partial T)$ and $\alpha_{\text {thermal }}=-\rho_{a} C_{D}|U|\left[C_{p}^{a}\left(\partial T_{a} / \partial T\right)+L_{v}\left(\partial q_{a} / \partial T\right)\right]$ depend on the partial derivatives of $|U|^{\prime}, T_{a}^{\prime}$, and $q_{a}^{\prime}$ with respect to SSTA, which we calculate based on the covariance between SSTA and $|U|^{\prime}, T_{a}^{\prime}$, and $q_{a}^{\prime}$ when the
SSTA leads by one month, similar to Frankignoul et al. (1998), that is,

$$
\begin{gathered}
\frac{\partial|U|}{\partial T}=\frac{\operatorname{cov}\left[|U|^{\prime}, T^{\prime}(-1)\right]}{\operatorname{var}\left[T^{\prime}(-1)\right]} \\
\frac{\partial T_{a}}{\partial T}=\frac{\operatorname{cov}\left[T_{a}^{\prime}, T^{\prime}(-1)\right]}{\operatorname{var}\left[T^{\prime}(-1)\right]} \\
\frac{\partial q_{a}}{\partial T}=\frac{\operatorname{cov}\left[q_{a}^{\prime}, T^{\prime}(-1)\right]}{\operatorname{var}\left[T^{\prime}(-1)\right]}
\end{gathered}
$$

With the quantification of $\alpha$, the turbulent heat flux anomalies [Eq. (10)] can be partitioned as

$$
-Q_{\mathrm{SH}}^{\prime}-Q_{\mathrm{LH}}^{\prime}=-\alpha T^{\prime}+Q_{\mathrm{res}}^{\prime} .
$$

The term $Q_{\text {res }}^{\prime}=-Q_{\mathrm{SH} \_ \text {res }}^{\prime}-Q_{\mathrm{LH} \_ \text {res }}^{\prime}$ is the residual of turbulent heat flux anomalies from the damping mechanism, which is independent of SSTA and represents turbulent heat flux anomalies due to atmospheric variability. In our analysis, we assume that the radiative heat flux 
$\left(Q_{\mathrm{SW}}^{\prime}-Q_{\mathrm{LW}}^{\prime}\right)$ is mainly determined by the atmosphere (Frankignoul and Kestenare 2002). Collecting terms, we quantify $Q_{\mathrm{atmo}}^{\prime}=Q_{\mathrm{sw}}^{\prime}-Q_{\mathrm{lw}}^{\prime}+Q_{\mathrm{res}}^{\prime}$ as the atmospheric contribution to the net surface heat flux anomaly and

$$
Q_{\mathrm{net}}^{\prime}=-\alpha T^{\prime}+Q_{\mathrm{atmo}}^{\prime} .
$$

Substituting Eq. (16) into Eq. (2), we formulate the mixed layer heat balance as

$$
\frac{\partial T^{\prime}}{\partial t}=\underbrace{\frac{\alpha T^{\prime}}{\rho_{o} C_{p}^{o} \bar{h}_{m}}}_{\text {Term A }}+\underbrace{\frac{Q_{\text {atmo }}^{\prime}}{\rho_{o} C_{p}^{o} \bar{h}_{m}}}_{\text {Term B }\left(H_{\text {atmo }}\right)}-\underbrace{\frac{\overline{Q_{\text {net }}} h_{m}^{\prime}}{\rho_{o} C_{p}^{o}\left(\bar{h}_{m}\right)^{2}}}_{\text {Term C }\left(H_{\text {MLD }}\right)}+\underbrace{H_{\text {ocean }}^{\prime}}_{\text {Term D }} .
$$

With this formulation, the SSTA tendency is attributed to SSTA damping by turbulent heat flux(term A), forcing by the atmospheric heating (term B), temperature changes due to interannual MLD variability (term C), and heating anomalies due to oceanic processes (term D).

To isolate the atmospheric thermal forcing on AMV SSTA, we first set the MLD term $H_{\mathrm{MLD}}$ and the oceanic heat transport $H_{\text {ocean }}^{\prime}$ term to zero in the mixed layer heat balance model [Eq. (17)]. In addition, given that the atmosphere has very short memory, we assume the atmospheric heating term $H_{\text {atmo }}$ to be white noise, which is formulated as a normal distribution function, $N\left(0, \sigma^{2}\right)$. The distribution parameter $\sigma$ is the standard deviation (STD) of $H_{\text {atmo }}$. Further, we define the $e$-folding time of SSTA as

$$
\tau=\frac{\rho_{o} C_{p}^{o} \bar{h}_{m}}{\alpha} .
$$

With the above assumptions and simplifications, the mixed layer heat balance [Eq. (17)] is conceptualized as a red-noise model (Hasselmann 1976):

$$
\frac{\partial T^{\prime}}{\partial t}=\frac{-T^{\prime}}{\tau}+N\left(0, \sigma^{2}\right) .
$$

The model consists of only two parameters, $\tau$ and $\sigma$. In our analysis, both parameters are derived from observations (see section $2 b$ ).

We simulate atmospheric heating-forced SSTA by integrating the red-noise model [Eq. (19)] for 200 years. The simulation is repeated 1000 times to estimate the SSTA standard deviation (STD) and quantify its uncertainty range. In this study, the uncertainty range is defined as the $95 \%$ confidence interval of SSTA STD derived from the 1000 simulations.

\section{b. Observation-based datasets}

All data used in this study, except the aerosol radiative forcing, are from observation-based sources. The SSTs

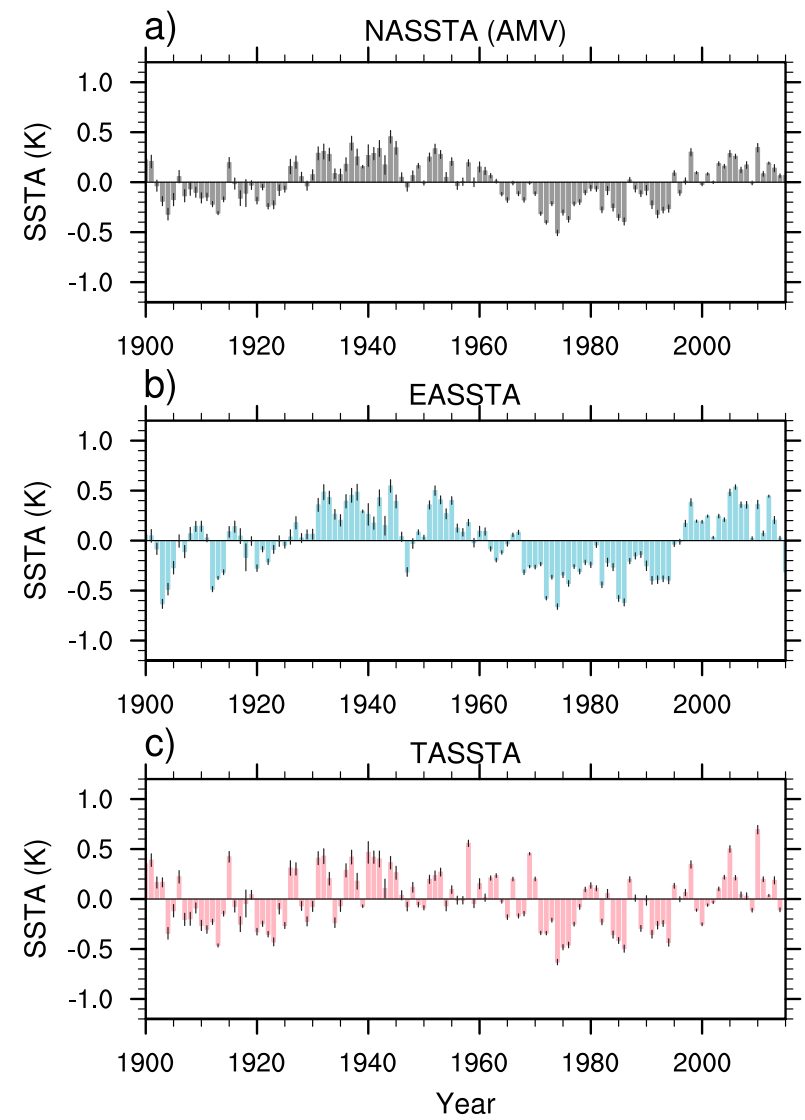

FIG. 1. The 1900-2015 annual-mean SSTA averaged over the (a) North Atlantic (AMV index), (b) extratropical North Atlantic $\left(40^{\circ}-65^{\circ} \mathrm{N}, 60^{\circ}-10^{\circ} \mathrm{W}\right)$, and (c) tropical North Atlantic $\left(5^{\circ}-20^{\circ} \mathrm{N}\right.$, $\left.75^{\circ}-20^{\circ} \mathrm{W}\right)$. All three SSTA time series have been detrended. The bars are the SSTA calculated as the mean from the five SSTA datasets, and the error bars are the $95 \%$ confidence interval of the mean.

used to construct the AMV index [SSTA ${ }^{1}$ averaged over the entire North Atlantic (NASSTA), as shown in Fig. 1a) extends from 1900 to 2016 and are from five datasets: the Extended Reconstructed SST (ERSST), version 4 (Huang et al. 2015; Liu et al. 2015), the Centennial in situ Observation-Based Estimates (COBE) SST (Hirahara et al. 2014), the Hadley Centre Sea Ice and Sea Surface Temperature dataset (HadISST) (Rayner et al. 2003), the International Comprehensive OceanAtmosphere Dataset (ICOADS) (Worley et al. 2005), and Kaplan SST (Kaplan et al. 1998). To reflect regional features associated with the AMV, we define the extratropical (tropical) North Atlantic SSTA index as SSTA averaged over $40^{\circ}-65^{\circ} \mathrm{N}, 60^{\circ}-10^{\circ} \mathrm{W}\left(5^{\circ}-20^{\circ} \mathrm{N}, 75^{\circ}-20^{\circ} \mathrm{W}\right)$

\footnotetext{
${ }^{1}$ The SSTA used to construct observed AMV (NASSTA), EASSTA and TASSTA indices has been detrended and deseasonalized.
} 
TABLE 1. Information about the ICOADS, NCEP-NCAR, and 20CR datasets. When calculating the damping coefficients $\alpha$ based on the average of the three datasets, the value derived from individual datasets are interpolated into a $1 \times 1$ grid cell to match the EN4.2.1 dataset.

\begin{tabular}{lccc}
\hline \multicolumn{1}{c}{ Dataset } & $\begin{array}{c}\text { Horizontal resolution } \\
(\text { lat } \times \text { lon })\end{array}$ & $\begin{array}{c}\text { Temporal } \\
\text { coverage }\end{array}$ & \multicolumn{1}{c}{ Notes } \\
\hline ICOADS & $2.0^{\circ} \times 2.0^{\circ}$ & $1950-2016$ & $\begin{array}{c}\text { Only data after the 1950s are used in this study due to low data coverage } \\
\text { prior to this decade. At each grid cell, missing observations are filled } \\
\text { using linear interpolation before calculating the SSTA lead-1 } \\
\text { correlation. } \\
\text { The monthly mean of surface wind speed is calculated from the 6-hourly } u \\
\text { and } v \text { wind. }\end{array}$ \\
20CR & $2.5^{\circ} \times 2.5^{\circ}$ & $1948-2016$ & $\begin{array}{c}\text { The monthly mean of surface wind speed is calculated from the 6-hourly } u \\
\text { and } v \text { wind. }\end{array}$ \\
\hline
\end{tabular}

(Figs. 1b,c), where AMV explains a significant portion of SSTA variance. According to our analysis, the SSTA indices are highly consistent among the five datasets, as the data spread is an order of magnitude smaller than the average SSTA (Fig. 1). This consistency applies to all three SSTA indices, even in the early part of the record where SST observations are relatively sparse (Fig. 1).

The parameters that define the red-noise model [Eq. (19)], namely the $e$-folding time $\tau$ and the STD of atmospheric heating rate $\sigma$, are also derived from observation-based datasets. Specifically, deriving $\tau$ involves a quantification of SSTA damping rate by surface heat flux $\alpha$ [Eqs. (10)-(14)] and an estimation of ocean mixed layer depth (MLD) [Eq. (18)]. The SSTA damping rate $\alpha$ [Eqs. (10)-(14)] is calculated using the oceanic and meteorological variables archived by ICOADS, the Twentieth Century Reanalysis (20CR) (Compo et al. 2011), and the National Centers for Environmental PredictionNational Center for Atmospheric Research (NCEPNCAR) reanalysis (Kalnay et al. 1996). Information about the three datasets and about data usage is summarized in Table 1.

The MLD is derived from the gridded monthly temperature and salinity fields from EN4.2.1 (Good et al. 2013) using the potential density criteria of $\Delta \rho=$ $0.125 \mathrm{~kg} \mathrm{~m}^{-3}$ (de Boyer Montégut et al. 2004). MLDs derived from EN4.2.1 are consistent with MLDs derived from Argo profiles (Holte et al. 2017; Argo 2019) over the North Atlantic (Fig. 2). We opt to use EN4.2.1 for MLD climatology due to its longer temporal coverage. To calculate the $e$-folding time for the red-noise model [Eq. (18)], the climatological (1950-2009) MLD is used and the damping coefficients $\alpha$ are from the average of the ICOADS, NCEP-NCAR, and 20CR datasets (Table 1).

The heating rate due to atmospheric forcing $H_{\text {atmo }}$ [term B in Eq. (17)] is derived from the 20CR and NCEP-NCAR datasets. We first calculate $H_{\text {atmo }}$ for each individual month from $Q_{\mathrm{atmo}}^{\prime}$ and the climatological
MLD for that month during 1900-2016 (1900-2012 for the 20CR and 1948-2016 for NCEP/NCAR), and then derive $\sigma$ as the STD of $H_{\text {atmo }}$. Over the extratropical North Atlantic, $\sigma$ is $0.074 \mathrm{~K}$ month $^{-1}$. This value increases to $0.27 \mathrm{~K}$ month $^{-1}$ over the tropical North Atlantic. It is noteworthy that $\sigma$ is the STD of atmospheric thermal forcing rather than surface heat flux. The former is the effective heating rate that the surface heat flux will generate throughout the entire mixed layer, and is weighted by the inverse of the MLD. The deep mixed layer in the extratropical North Atlantic makes the surface heat flux less effective in generating temperature anomalies than in the tropical ocean.

When performing simulations with the red-noise model, the uncertainties in the $e$-folding time $\tau$ and the STD of atmospheric heating rate $\sigma$ are taken into account. Specifically, we used a bootstrap method to subsample the EA/TA $\tau-\sigma$ parameter sets (i.e., we randomly draw half of the EA or TA grid cells and calculate the area-weighted average of $\tau$ and $\sigma$ ) 1000 times from the parameters derived from all three datasets. The uncertainties in the parameters are incorporated into the red-noise model simulations. From these simulations, we find that the uncertainties in model parameters contribute $20 \%$ ( $9 \%$ ) of the simulated SSTA STD uncertainty in the tropical (extratropical) North Atlantic.

\section{c. Climate model simulations of aerosol forcing on $A M V$}

To quantify the contribution of anthropogenic aerosol to AMV SSTA, we analyze the output of five models from phase 5 of the Climate Model Intercomparison Project (CMIP5) that provide multiple ensemble members for the Anthropogenic Aerosol simulations (Table 2). In these idealized experiments, only anthropogenic aerosols are considered as a forcing agent for the twentieth-century (1900-2006) climate (Taylor et al. 2012). 

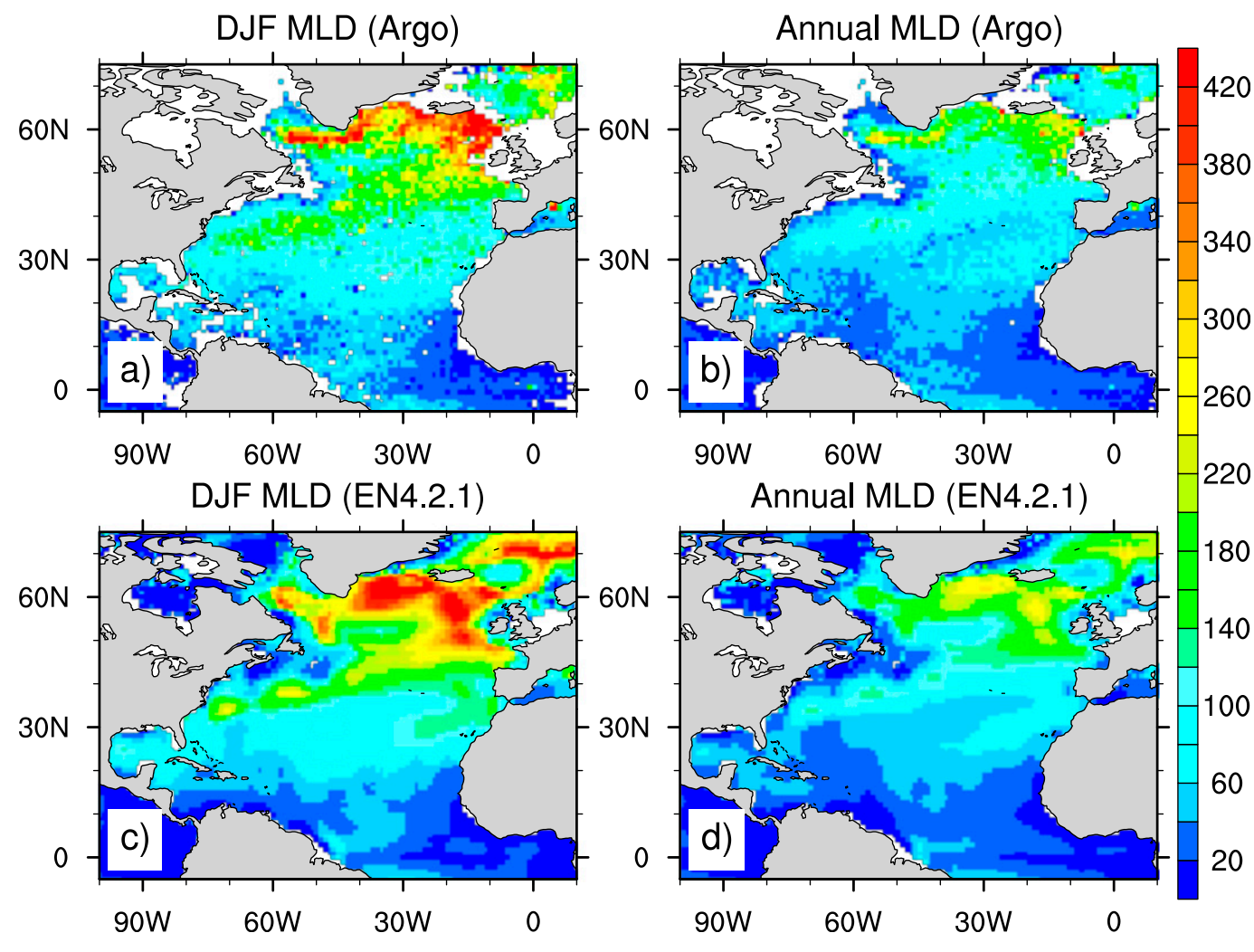

FIG. 2. (a),(c) DJF and (b),(d)annual-mean MLD in the North Atlantic Ocean calculated using (a),(b) Argo profile data and (c),(d) the EN4.2.1 data archive.

We first calculate AMV SSTA in each ensemble member, and then use the unweighted mean among ensemble members to represent the response of SSTA to aerosol forcing in each model. Without other forcing agents, the model-simulated AMV SSTA STD is attributable to aerosol forcing (Table 2). Here, we assume that aerosol forcing and atmospheric heating are mutually independent, in that they show distinct power spectra in the frequency domain (Booth et al. 2012; Bellucci et al. 2017). Thus, SSTA variability generated by the combination of atmospheric heating and anthropogenic aerosol is estimated as $\sqrt{\sigma_{\text {atmo }}^{2}+\sigma_{\text {aerosol }}^{2}}$.

\section{Contribution of the extratropical and tropical North Atlantic to the AMV}

Although the AMV is a basin-scale mode (Schlesinger and Ramankutty 1994; Kerr 2000), it exhibits important spatial variability relevant to this study. The positive AMV phase, manifested as a basin-scale warming, has two centers of action: one located in the extratropical North Atlantic (EASSTA; $40^{\circ}-65^{\circ} \mathrm{N}, 60^{\circ}-10^{\circ} \mathrm{W}$ ) and the other in the tropical North Atlantic (TASSTA $; 5^{\circ}-20^{\circ} \mathrm{N}$, $75^{\circ}-20^{\circ} \mathrm{W}$ ) (Fig. 3a).
While the SSTA in both regions is highly correlated with the AMV, the persistence of the SSTA signal is markedly different between the regions. Based on monthly SSTA data, the autocorrelation function of the EASSTA shows a parallel with the AMV SSTA (i.e., NASSTA): both slowly weaken until they become statistically insignificant after 12 years $^{2}$ (Fig. 3b). In contrast, the TASSTA shows considerably less persistence. Its autocorrelation decays quickly, becoming insignificant within three years (Fig. 3b). Figure $3 b$ suggests that the quick decay of TASSTA after a year cannot explain the long persistence of AMV SSTA. However, the observed TASSTA does show a significant power spectrum at the decadal-to-multidecadal time scale. To verify that the sharp decrease of TASSTA autocorrelation is not a result of the relatively noisy tropical SSTA, we

\footnotetext{
${ }^{2}$ The statistical significance ( $\alpha=0.05$ level) is determined using the estimator $t=1.96 / \sqrt{N-d}$, where $N$ is the length of the time series and $d$ is the lag. The null hypothesis that the autocorrelation is not significantly different from 0 is rejected if $|\mathrm{ACF}|>t$. According to Figs. $3 b$ and $3 c$, the ACF of EASSTA becomes statistically insignificant (i.e., when $|\mathrm{ACF}|<t$ and the null hypothesis should be accepted) when time lag $d$ increases to 149 months (about 12 years).
} 
TABLE 2. Information about CMIP5 models used in this study. In the resolution column, nLat and nLon indicate the number of grid points in the latitudinal and longitudinal directions, respectively. In the NASSTA (index used to define AMV in observations) STD column, the number in the parentheses is the SSTA STD calculated using detrended time series.

\begin{tabular}{lccr}
\hline \hline \multicolumn{1}{c}{ Model } & $\begin{array}{c}\text { Resolution (nLat } \times \\
\text { nLon, level) }\end{array}$ & $\begin{array}{c}\text { Ensemble } \\
\text { members }\end{array}$ & $\begin{array}{c}\text { NASSTA } \\
\text { STD (K) }\end{array}$ \\
\hline CCSM4 & $192 \times 288$, L26 & 3 & $0.06(0.026)$ \\
CanESM2 & T63, L35 & 5 & $0.165(0.039)$ \\
CSIRO-Mk3.6.0 & T63, L18 & 5 & $0.07(0.066)$ \\
GISS-E2-H & $89 \times 144$, L39 & 5 & $0.08(0.011)$ \\
GISS-E2-R & $89 \times 144$, L39 & 5 & $0.03(0.025)$ \\
\hline
\end{tabular}

recalculate the autocorrelation using annual-mean SSTA (Fig. 3c). We start the AMV year in April in order to make the winter season contiguous (December-February). As seen in Fig. 3c, the autocorrelation functions of TASSTA, EASSTA, and AMV SSTA are almost identical to those calculated using monthly data (Fig. 3b). TASSTA decays quickly after one year, but the EASSTA and AMV SSTA persist. This EASSTA/TASSTA difference shows that the slowly varying feature of AMV SSTA mainly results from the extratropical branch (Wills et al. 2019).

The importance of the extratropical branch to the AMV is also apparent in the temporal evolution of the AMV SSTA (Fig. 4). Four to five years prior to the maximum AMV, there is a significantly positive SSTA in the extratropical North Atlantic, but no detectable SSTA appears in the tropical North Atlantic (Figs. 4a,b). At the same time, surface winds are manifested as an intensification of the westerlies along $45^{\circ} \mathrm{N}$ and thus the enhancement of cyclonic circulation (low pressure) in the subpolar region (Fig. 4b), resembling a positive phase of the North Atlantic Oscillation (NAO) (Timmermann et al. 1998; Gastineau and Frankignoul 2015; RuprichRobert and Cassou 2015; Delworth et al. 2017). Subsequently, the SSTA in the extratropical North Atlantic spreads into the tropical ocean one year before the AMV peak and forms a horseshoe-like AMV SSTA pattern (Figs. 3a and 4e). Accompanying the horseshoe-like SSTA, surface wind shows weakened westerlies in the midlatitudes $\left(40^{\circ}-50^{\circ} \mathrm{N}\right)$, as well as a weakened subpolar cyclone and subtropical anticyclone (Figs. 4e,f). Such a circulation pattern resembles a negative phase of NAO, and favors warm SSTA in the tropical ocean through cloud-radiative feedback (Seager et al. 2003; Brown et al. 2016). The AMV reaches its peak positive phase with $0.6-\mathrm{K}$ warming in the extratropical North Atlantic and 0.4-K warming in the tropics (Fig. 4f). Two to four years after the AMV peak, the warm SSTA persists in the extratropical North Atlantic but disappears
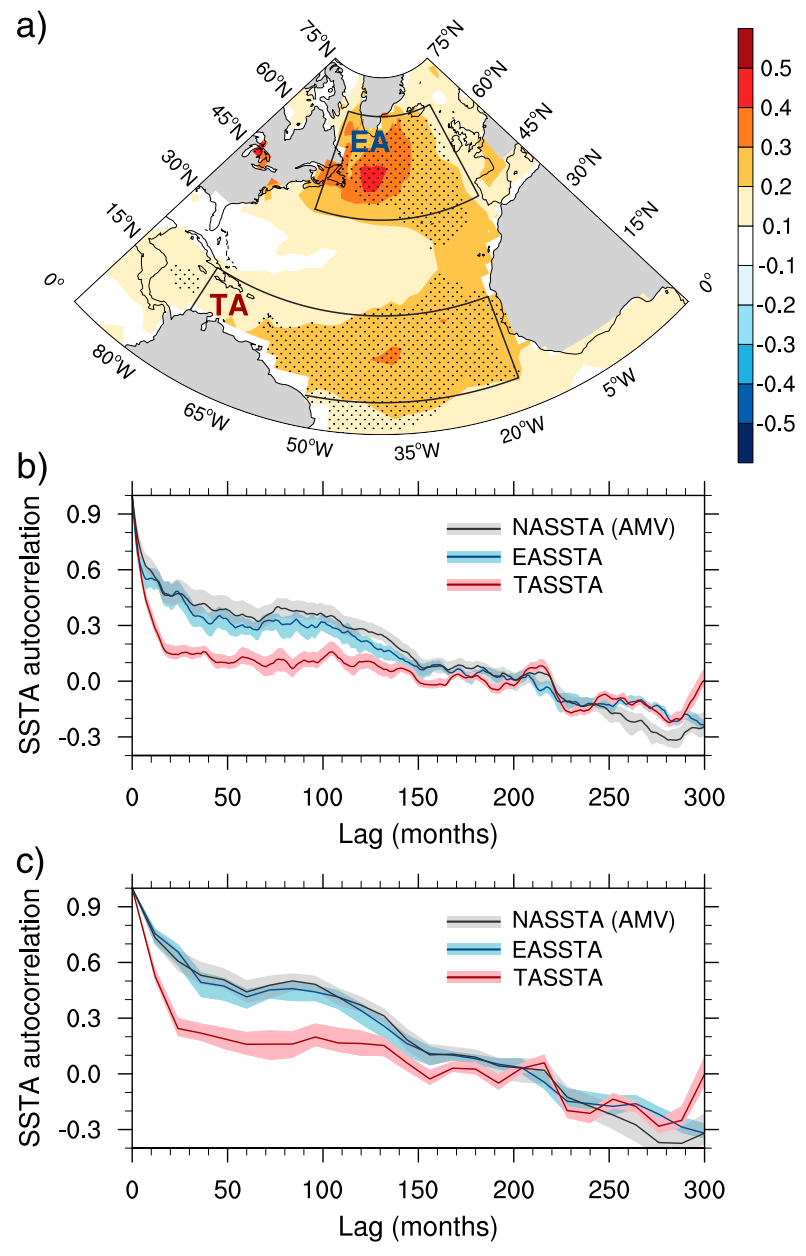

FIG. 3. (a) SSTA regression upon the AMV index (Fig. 1a). The stippled region is where the AMV index explains more than $30 \%$ of local SSTA variance. The black boxes denote the extratropical North Atlantic and tropical North Atlantic. (b) Autocorrelation function of AMV SSTA (black curve), extratropical North Atlantic SSTA (EASSTA; blue curve), and tropical North Atlantic SSTA (TASSTA; red curve). The shading on the curves represents the uncertainty range of the SSTA autocorrelation function as derived from the five SST datasets. The SSTA indices have monthly resolution. (c) As in (b), but using the annual indices with AMV year starting in April and ending in the following March to make the winter season contiguous.

in the tropical North Atlantic (Figs. 4g-j). Given these important differences in the tropical and extratropical regions (Drews and Greatbatch 2017; Wills et al. 2019), we separately model these domains to assess the impact of atmosphere-only forcing on their SST variability.

\section{Modeling an atmosphere-forced ocean mixed layer}

We next model the mixed layer heat balance over the two spatial domains outlined in Fig. 3a. The SSTA 

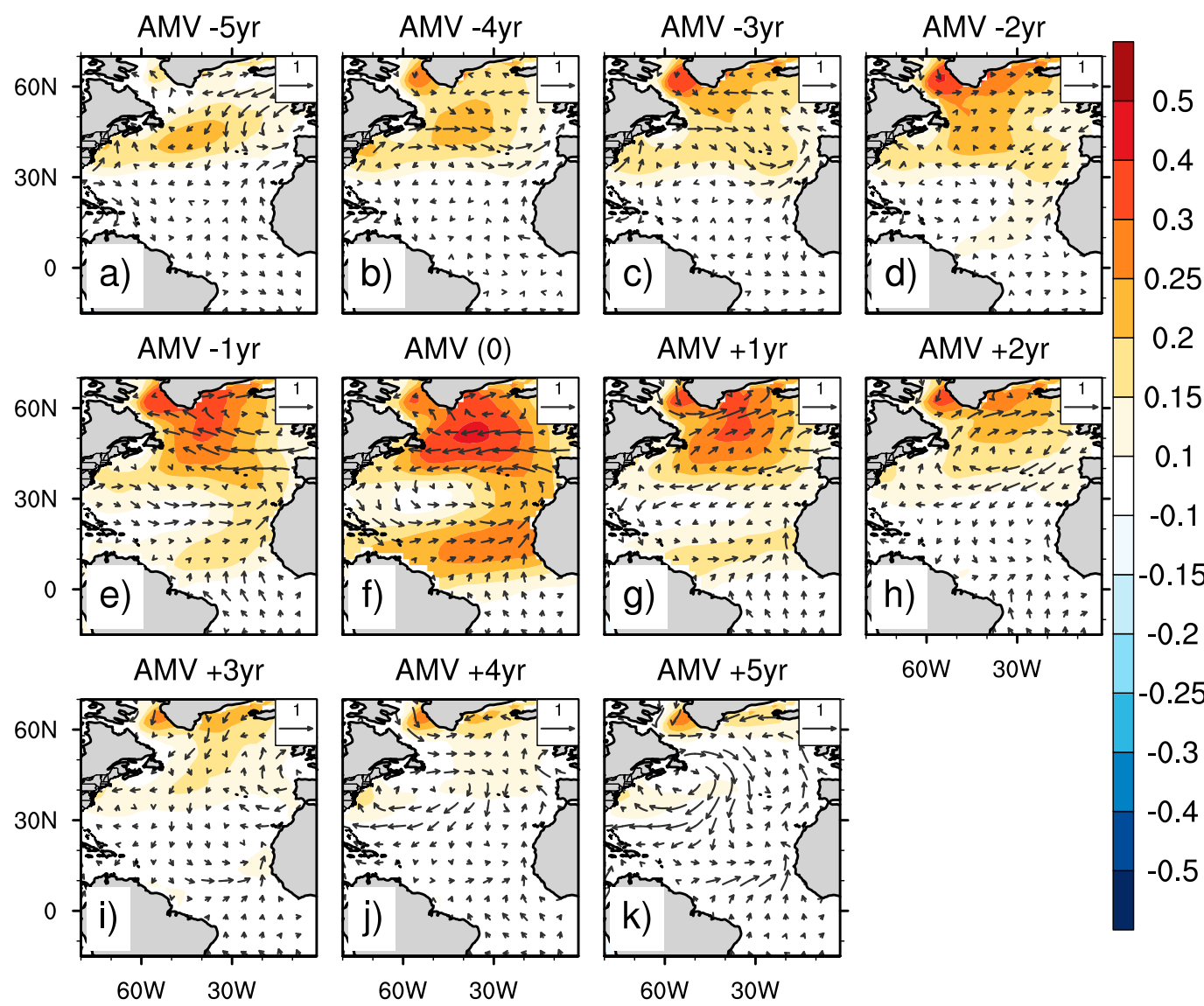

FIG. 4. Lead-lag regression of SSTA (shaded; K) and surface wind anomalies (vectors; $\mathrm{m} \mathrm{s}^{-1}$ ) onto the AMV index shown in Fig. 1a: (a)-(e) SSTA and the wind anomalies leading the AMV peak by 5 to 1 years, respectively, (f) SSTA and wind anomalies during the AMV peak, and (g)-(k) SSTA and wind anomalies lagging the AMV peak by 1 to 5 years, respectively. The SSTA value is calculated as the regression coefficients given one STD of AMV index, and is based on the ERSSTv4 dataset; the surface wind is from the 20CR.

tendency in the mixed layer is the result of damping by the turbulent sensible and latent heat fluxes, atmospheric heating, interannual variability of MLD, and heating due to oceanic processes [Eq. (17)]. To isolate the contribution of atmospheric forcing on SSTA variability in the extratropical and tropical North Atlantic, we conceptualize mixed layer heat balance as a red-noise model in which SSTA is forced exclusively by atmospheric heating $H_{\text {atmo }}$ [term $\mathrm{B}$ in Eq. (17), which is approximated as a normally distributed white noise] and damped at a rate of $T^{\prime} / \tau$ due to the dependence of turbulent heat fluxes on SSTA [Eq. (19)].

\section{a. The e-folding time scale of North Atlantic SSTA}

In the red-noise model [Eq. (19)], the $e$-folding time scale of SSTA, denoted by $\tau$, a measure of persistence, is set by the MLD and a damping coefficient $\alpha$ that depends on meteorological conditions at the sea surface
[Eqs. (10)-(14)]. Deep (shallow) MLDs and weak (strong) damping lead to long (short) $e$-folding time scales and more (less) persistent SSTA.

We first calculate the damping coefficients $\alpha$ [Eqs. (10)-(14)] over the North Atlantic based on air-sea parameters from the ICOADS, NCEP-NCAR reanalysis, and 20CR datasets. All three datasets show strong SSTA damping by turbulent heat fluxes south of the Gulf Stream extension, and relatively weak damping over the extratropical North Atlantic (Figs. 5a,e,i). The datasets, however, differ in their damping over the tropical oceans. ICOADS shows a damping coefficient close to $35 \mathrm{~W} \mathrm{~m}^{-2} \mathrm{~K}^{-1}$ (Fig. 5a), while the damping is weaker than $20 \mathrm{~W} \mathrm{~m}^{-2} \mathrm{~K}^{-1}$ in both NCEP-NCAR (Fig. 6e) and 20CR (Fig. 5i). Since the three datasets generally agree on the magnitude of $\alpha_{\text {self }}$ and $\alpha_{\text {thermal }}$ over the tropics (Figs. 5b,d,f,h,j,l), this spread in damping coefficients likely results from uncertainties in the response of wind speed to SSTA $\left(\alpha_{|U|}\right)$. Specifically, $\alpha_{|U|}$ 

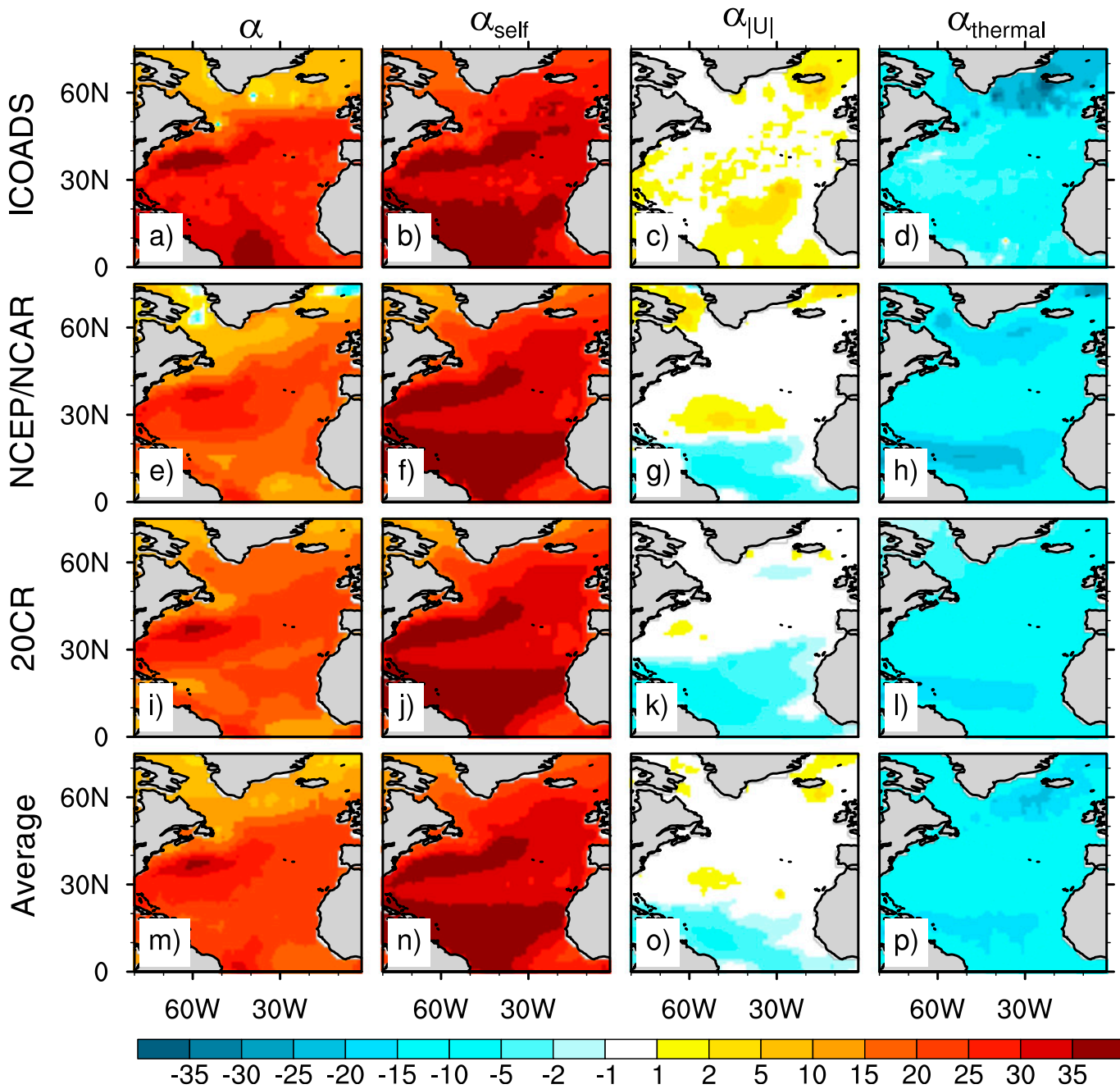

FIG. 5. SSTA damping coefficients and its subcomponents (shaded; $\mathrm{W} \mathrm{m}^{-2} \mathrm{~K}^{-1}$ ): (left to right) $\alpha, \alpha_{\text {self }}, \alpha_{|U|}$, and $\alpha_{\text {thermal }}$, calculated according to Eqs. (10)-(14). Rows show estimates (a)-(d) using ICOADS, (e)-(h) based on NCEP-NCAR, and (i)-(l) based on the 20CR dataset, as well as (m)-(p) the average of the three datasets.

is weakly positive $\left(1-2 \mathrm{~W} \mathrm{~m}^{-2} \mathrm{~K}^{-1}\right)$ over the tropical North Atlantic in ICOADS ${ }^{3}$ (Fig. 5c), but is moderately negative (about $-10 \mathrm{~W} \mathrm{~m}^{-2} \mathrm{~K}^{-1}$ ) in NCEPNCAR (Fig. 5g) and 20CR (Fig. 5k). The negative values of $\alpha_{|U|}$ in the two reanalysis datasets are consistent with the observed "wind-evaporation-SSTA feedback" mechanism in the tropical ocean, in which a positive SSTA weakens the wind and evaporation, thus maintaining the warm SSTA (Xie and Philander 1994).

\footnotetext{
${ }^{3}$ The uncertainties in tropical $\alpha_{|U|}$ calculated using ICOADS datasets might come from the large number of missing wind observations $(>5 \mathrm{yr})$ which were filled in using spatial interpolation in our calculation.
}

To minimize uncertainties in $\alpha_{|U|}$ introduced by different datasets, we quantify the damping coefficients $\alpha$ using the average of the three datasets (Figs. $5 \mathrm{~m}-\mathrm{p}$ ). Over most of the subtropical gyre, the damping coefficient is $\sim 20 \mathrm{~W} \mathrm{~m}^{-2} \mathrm{~K}^{-1}$, a value similar to that obtained by Frankignoul et al. (1998) and Frankignoul and Kestenare (2002), who derived $\alpha$ directly from the lead-lag covariance between turbulent heat flux and SSTA. SSTA damping is maximum south of the Gulf Stream, but is relatively weak over the extratropical North Atlantic, especially over the subpolar gyre (Fig. 5m), which likely results from a combination of weak self-damping due to a cold background SST (Fig. 5n) and a relatively strong thermal adjustment to SSTA (Fig. 5p). The tropical damping coefficients calculated here are stronger than those in Frankignoul 

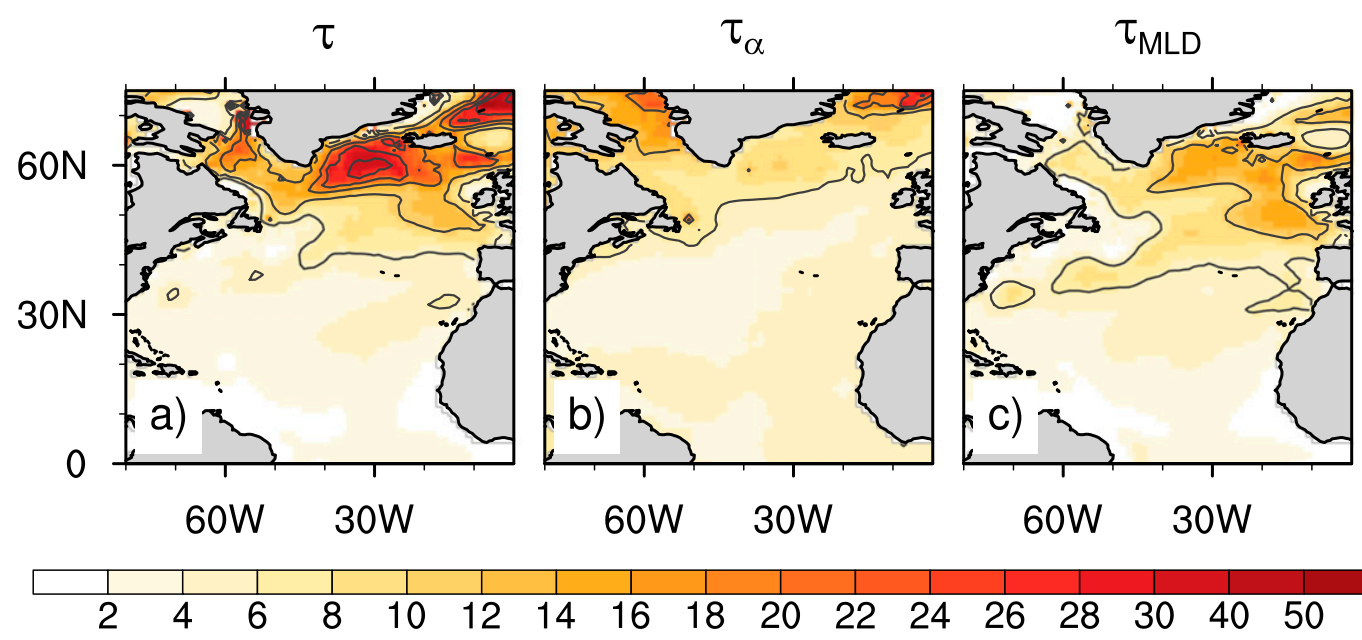

FIG. 6. (a) The SSTA $e$-folding time scale in the North Atlantic with $\tau$ calculated according to Eq. (18). (b) As in (a), but with mixed layer depth (MLD) equal to its basin average over the North Atlantic. (c) As in (a), but with basin-averaged $\alpha$. Color shading (contours) indicates the $e$-folding time scale calculated using the annual-mean (wintertime) MLD. The contour interval is 10 months.

and Kestenare (2002) due to the assumptions made for their algorithms. ${ }^{4}$

The $e$-folding time scale of SSTA $(\tau)$, is proportional to MLD $\left(h_{m}\right)$ and inversely related to the damping coefficient $(\alpha)$ [Eq. (18)]. The two variables together determine the spatial gradient of $\tau$ over the North Atlantic, which is longer in the extratropics than in the tropics (Fig. 6a). Averaged over the extratropics, the SSTA $e$-folding time is 11.8 months with an annual-mean MLD (colors in Fig. 6a) and 19.5 months with DJF MLD (contours in Fig. 6a), which represents the maximum SSTA memory (Buckley et al. 2019). The $e$-folding time decreases significantly with decreasing latitude, and drops to 2.4 months over the tropical oceans (Fig. 6a). This latitudinal change results from both the nonuniform distribution of MLD (Figs. 2 and $6 \mathrm{~b}$ ) over the North Atlantic and the spatial heterogeneity of the damping coefficient (Figs. $5 \mathrm{~m}$ and $6 \mathrm{c}$ ).

The contribution of spatial variations in MLD and the damping coefficients to the spatial distribution of SSTA

\footnotetext{
${ }^{4}$ The algorithm to quantify air-sea heat flux feedback developed in Frankignoul and Kestenare (2002) [their Eqs. (1)-(3)] is based on the assumption that atmospheric variables have much shorter memory than SSTA. This assumption may be violated in the tropical oceans where the SSTA $e$-folding time scale is several months (Fig. 7a) and is comparable to atmospheric memory. The low SSTA autocorrelation in the tropics might lead to artificially strong feedback (weak damping) based on the algorithm in Frankignoul and Kestenare (2002). In addition, using SSTA lead covariance matrix with heat flux might underestimate the selfdamping mechanism, in that the self-damping depends on instantaneous SSTA rather than on pre-existing SSTA. These two factors could lead to a weaker SSTA damping if using the algorithm in Frankignoul and Kestenare (2002).
}

$e$-folding time is further quantified in Fig. 7. Over the entire North Atlantic, the $e$-folding time calculated with basin-averaged MLD $\left(\tau_{\alpha}\right)$ explains $34 \%$ of the spatial variance of annual-mean $\tau$ (Fig. 7a), while the $e$-folding time with basin-averaged $\alpha\left(\tau_{\mathrm{MLD}}\right)$ explains $59 \%$ (Fig. 7b). Over the tropical and subtropical oceans, $\tau_{\alpha}$ can only explain $6 \%$ of the variance of $\tau$ (Fig. 7a), while $\tau_{\mathrm{MLD}}$ explains $85 \%$ of the $\tau$ variance (Fig. $7 \mathrm{~b}$ ). Thus, over the tropical and subtropical oceans, MLD is largely responsible for generating the observed $e$-folding time (Fig. 7b). The variance of $\tau$ explained by $\tau_{\alpha}$ increases to $17 \%$ over the extratropical oceans, but is still significantly lower than that explained by the MLD gradient (53\%) (Figs. 7a,b). The importance of MLD to the spatial distribution of $e$-folding time scale is similar for when DJF MLD is considered (Figs. 7c,d).

In summary, the mixed layer is deep in the extratropics (Fig. 2), and the damping is relatively weak due to the collective impact of cold SSTs as the background state [Eqs. (9) and (10); Figs. 5b,f,j,n] and an efficient adjustment of the atmosphere to the SSTA (Figs. 5d,h,l,p). Consequently, an SSTA in the extratropical North Atlantic can be preserved for a longer period compared to its tropical counterpart (Fig. 6a). This difference in persistence is consistent with the autocorrelation of EASSTA and TASSTA (Figs. 3b,c), as well as the temporal evolution of AMV SSTA (Fig. 4).

\section{b. Comparison of modeled and observed AMV SSTA variability: Atmosphere-only scenario}

The $e$-folding time $\tau$ and the STD of atmospheric heating rate $\sigma$ are first evaluated at each grid cell and then averaged over the extratropical and tropical boxes 

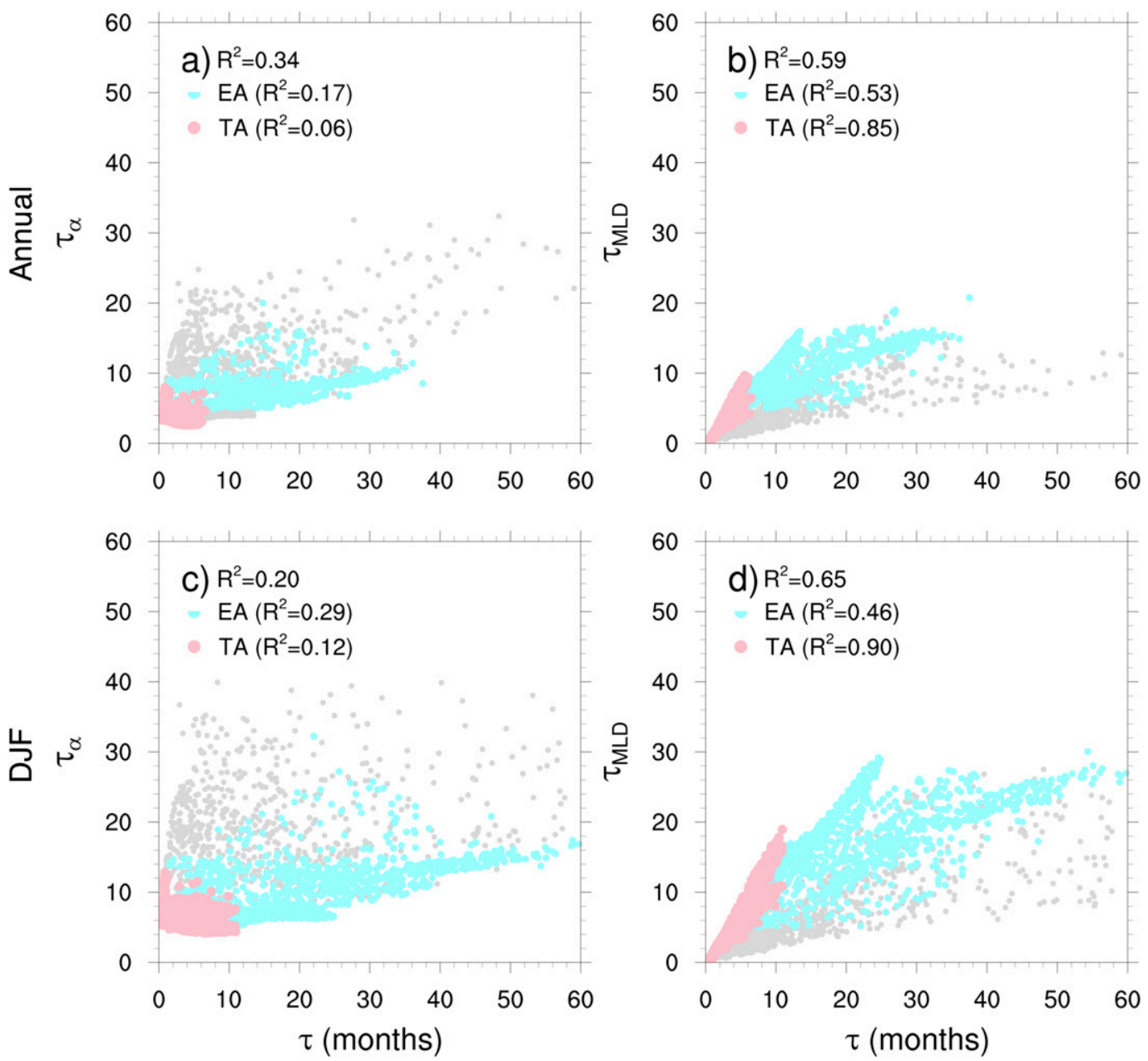

FIG. 7. Scatterplot of the SSTA $e$-folding time scale $\tau$ vs (a) $\tau$ calculated using spatially variable damping coefficients but with basin-averaged MLD $\tau_{\alpha}$, and (b) $\tau$ calculated using spatially variable MLD but basin-averaged damping coefficients $\tau_{\mathrm{MLD}}$. (c),(d) As in (a) and (b), but with the $e$-folding time scale calculated using DJF MLD. Red dots are from data in the tropical and subtropical $\left(0^{\circ}-40^{\circ} \mathrm{N}, 80^{\circ} \mathrm{W}-0^{\circ}\right)$ North Atlantic, blue dots are from data in the extratropical North Atlantic $\left(40^{\circ}-65^{\circ} \mathrm{N}, 60^{\circ}-10^{\circ} \mathrm{W}\right)$, and the gray dots are the grid cells in between the tropical/ subtropical and extratropical North Atlantic.

(delineated in Fig. 3a). We integrate the red-noise model [Eq. (19)] for 200 years for both the extratropical and tropical North Atlantic to quantify the magnitude of SSTA variability (represented by the STD of the 200-yr SSTA time series) forced purely by the atmosphere. The model is run with two scenarios, one using $\tau$ calculated with annual-mean variables, the other with $\tau$ calculated using DJF mean MLD. The latter run is expected to generate the longest SSTA memory as the MLD is the deepest during DJF months (Buckley et al. 2019). We have purposely used DJF MLD for $e$-folding time scale and the heating rate based on the monthly MLD in the second scenario, in order to produce what we consider an upper bound of SSTA variability generated by the atmospheric heating (Deser et al. 2003).
The red-noise model with atmospheric heating matches the observed SSTA variability in the tropical North Atlantic, but substantially underestimates the observed SSTA variability in the extratropics (Figs. 8a,b). Specifically, the model simulates an average SSTA STD of $0.33 \mathrm{~K}$ (pink box in Fig. 8a) for the tropical North Atlantic, close to the observed value (red lines in Fig. 8a), suggesting that atmospheric heating alone can explain tropical North Atlantic SSTA variability. Using an $e$-folding scale based on DJF MLD produces similar model results (red box in Fig. 8a). This result corroborates previous studies that emphasize the importance of atmospheric processes to the tropical branch of the AMV (Bellomo et al. 2016; Brown et al. 2016; Yuan et al. 2016; Wills et al. 2019). In contrast, the red-noise 


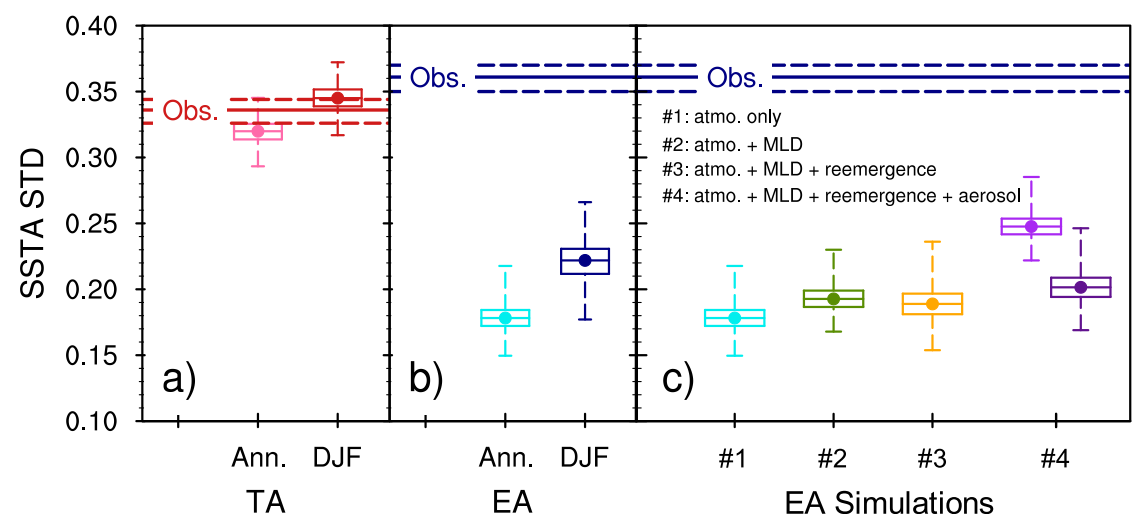

FIG. 8. North Atlantic SSTA variability with atmospheric forcing only. Box-and-whisker plot of SSTA STD (K) derived from 1000 simulations of the red-noise model [Eq. (19)]. The box represents the interquartile range and the horizontal line within the box represents the median of SSTA STD. The whiskers end at the maximum and minimum value of all simulations. The solid dot within each box is the mean of the SSTA STD. (a),(b) The STD of SSTA for the tropical and extratropical North Atlantic, respectively, forced with atmospheric heating only. The light red box in (a) [light blue box in (b)] shows the simulations with annual mean $\tau$; and the dark red (blue) box is that with DJF $\tau$. (c) The five boxes each represent a simulation for the extratropical North Atlantic SSTA STD. The light blue box is the simulation with atmospheric heating only [same as the light blue box in (b)], and the green box is the simulation with atmospheric heating and heating due to MLD variability [term C in Eq. (17)]. The orange box is the simulation with atmospheric heating, MLD variability, and the entrainment of SSTA from the previous winter (reemergence mechanism). The purple boxes are the SSTA STD considering the combination of atmospheric heating, MLD variability, reemergence, and the upper bound of the forcing of anthropogenic aerosols derived from CMIP5 models (Table 2). The light (dark) purple box is with the aerosol forcing calculated using the original (detrended) SSTA time series simulated by the CMIP5 models. The red solid line in (a) [blue solid line in (b) and (c)] is the observed SSTA STD in the tropical (extratropical) North Atlantic based on the average of the five SST datasets. The corresponding dashed lines are the $95 \%$ confidence interval of the observed SSTA STD.

model forced with atmospheric heating alone underestimates the observed magnitude of extratropical SSTA STD by $50 \%$. Specifically, the model simulates an average SSTA STD in the extratropical North Atlantic of $0.18 \mathrm{~K}$ (light blue box in Fig. $8 \mathrm{~b}$ ), which falls short of the observed value of $0.36 \mathrm{~K}$ (blue lines in Fig. 8b). The upper bound of the distribution is also well below the observed value. Using an $e$-folding time scale based on DJF MLD shortens the distance between the observed and modeled SSTA STD, but still underestimates the observed SSTA STD by $41 \%$ (blue box in Fig. 8b).

To test under what conditions the red-noise model can produce atmospherically forced SSTA comparable to observed values we explore the relationship between SSTA variability and the two model parameters: $e$-folding time $\tau$ and the STD of the atmospheric heating rate $\sigma$. Since SSTA STD increases monotonically with the $e$-folding time scale and with the STD of the atmospheric heating (Fig. 9), an increase in either could produce a model SSTA STD consistent with observations. Specifically, an increase in $\sigma$ from 0.074 to
$0.148 \mathrm{~K} \mathrm{month}^{-1}$ or an increase in $\tau$ from 11 months to 60 months could generate a match with observations. However, neither scenario is realistic within the current climate regime of the North Atlantic for the simple reason that there is a strong inverse relationship between $\tau$ and $\sigma$ in the observations; that is, an increase of $\tau$ is accompanied by a decrease of $\sigma$ (Fig. 9). This tradeoff stems from the mutual dependence of $\tau$ and $\sigma$ on the local MLD, where $\tau$ is proportional to MLD [Eq. (18)], but $\sigma$ is inversely proportional to MLD [term B in Eq. (17)]. Due to the inverse relationship between $\tau$ and $\sigma$ we can fit a function in the form of

$$
\ln \sigma=\beta_{1} \ln \tau+\beta_{2}+\varepsilon
$$

to describe the observed relationship between $\tau$ and $\sigma$. In other words, using our observed estimates of $\tau$ and $\sigma$, we fit a line between $\ln \sigma$ and $\ln \tau$. The constants $\beta_{1}$ and $\beta_{2}$ are derived so that the least squared error of the fitted function is minimized. For annual mean $\tau$, we find $\beta_{1}=-0.70, \beta_{2}=-0.89$, and $\varepsilon$ has zero mean with a standard deviation of 0.12 (Fig. 9), with the 


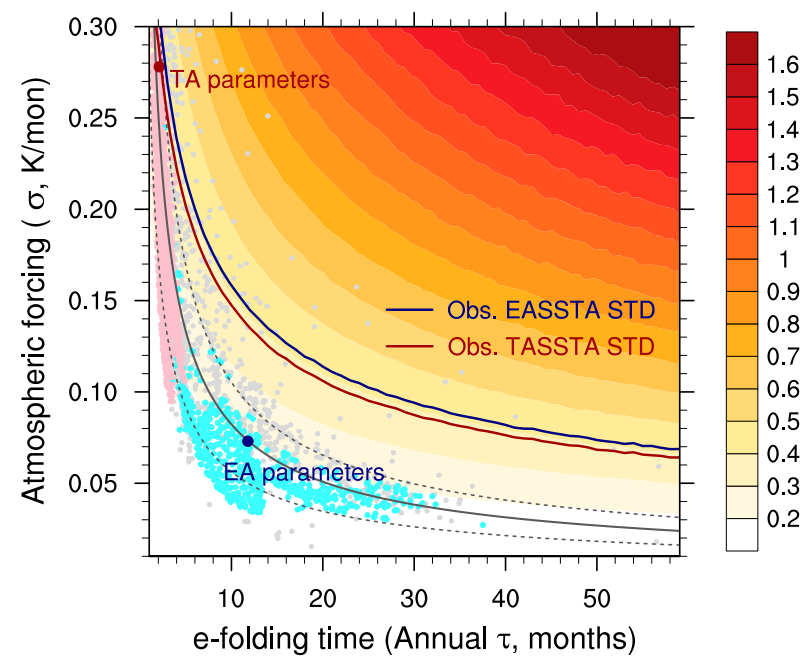

FIG. 9. SSTA STD as a function of $e$-folding time and the variability of atmospheric heating rate according to the red-noise model (shaded; K). The thick blue and red lines are the contours tracing the observed STD of EASSTA and TASSTA, respectively. The pink (light blue) dots show $\tau$ and $\sigma$ for all points in the tropical (extratropical) North Atlantic, and the gray dots are the remaining regions of the North Atlantic. The blue (red) dot is the domain averaged $e$-folding time and atmospheric heating rate in the extratropical (tropical) North Atlantic. The solid gray line is the bestfit relationship between $e$-folding time and atmospheric forcing in the North Atlantic, and the dashed gray lines show the $95 \%$ confidence interval derived from the log-log regression [Eq. (20)].

correlation between the fitted curve and the data being $0.86\left(R^{2}=0.74\right)$.

The trade-off between the two parameters has important implications for SSTA variability in response to atmospheric heating. Specifically, $\tau$ increases with MLD, and MLD variability explains $65 \%$ of the spatial variability in $\tau$ over the North Atlantic (Figs. $6 \mathrm{~b}$ and $7 \mathrm{c}, \mathrm{d}$ ). The increase in $e$-folding time will increase the SSTA STD if the atmospheric heating rate remains unchanged (Fig. 9). Meanwhile, an increase in MLD immediately weakens the effective heating rate by surface fluxes, since the heat is then distributed over a deeper water column [Eq. (17)]. This decreased variance for the atmospheric heating rate, in turn, decreases SSTA STD (Fig. 9).

Resulting from the mutual constraint between $\tau$ and $\sigma$ [Eq. (20)], the observed parameters are confined to a narrow domain of the theoretical parameter space (Fig. 9), making atmospheric thermal forcing an inefficient means to adjust the extratropical SSTA STD to that observed. In our analysis, the observed parameter space intersects with the observed EASSTA STD isoline in a narrow domain in which $\tau$ is less than 4 months and $\sigma$ is greater than $0.25 \mathrm{~K} \mathrm{month}^{-1}$, a parameter set representative of tropical rather than extratropical oceans (Fig. 9). This mismatch indicates that the atmosphere alone cannot force the extratropical SSTA variability unless the background state in the extratropical North Atlantic drastically shifts toward a tropical-like regime, an unlikely scenario under current climate conditions.

\section{c. The case for ocean dynamics contributing to the observed AMV SSTA variability}

The inability of atmospheric forcing alone to generate the observed SSTA variability over the extratropical North Atlantic suggests that other forcing components must be in play. These components include year-to-year MLD variability [term C in Eq. (17)], reemergence of the previous winter's SSTA (Alexander and Deser 1995; Hanawa and Sugimoto 2004), external forcing by natural and anthropogenic aerosols (Otterå et al. 2010; Booth et al. 2012; Bellucci et al. 2017), and 3D ocean dynamics (Delworth et al. 1993; Hausmann and Czaja 2012; Buckley et al. 2014, 2015; Buckley and Marshall 2016; Delworth et al. 2017; Zhang 2017; Zhao et al. 2018). We add the former three components to our model and infer the latter from the mismatch between the modeled and observed SSTA variability, because limited ocean observations preclude the explicit inclusion of 3D ocean dynamics. We assume that interannual MLD variability, entrainment of the previous winter's SSTA due to wintertime MLD deepening, and external forcing by anthropogenic aerosols are independent of each other. We add them sequentially to our model.

Year-to-year MLD variability yields an STD in the heating rate [term $\mathrm{C}$ in Eq. (17)] of $0.03 \mathrm{~K} \mathrm{month}^{-1}$, equivalent to $40.5 \%$ of the STD of the heating rate due to atmospheric forcing. The MLD-induced heating, together with atmospheric heating [the idealized heat balance equation becomes $\left(\partial T^{\prime} / \partial t\right)=\left(-T^{\prime} / \tau\right)+N\left(0, \sigma_{\text {atmo }}^{2}\right)+$ $\left.N\left(0, \sigma_{\text {MLD }}^{2}\right)\right]$, results in an SSTA STD of $0.19 \mathrm{~K}$, still far below that observed (green box in Fig. 8c).

Next, we include wintertime deepening of the MLD so that a previous winter's SSTA, preserved at the base of winter mixed layer, can be entrained. Following de Coetlogon and Frankignoul (2003), this SSTA reemergence mechanism is formulated as $\gamma_{t} T_{\text {preceding winter. }}^{\prime}$. Here, $\gamma_{t}$ is the entrainment rate and is defined as

$$
\gamma_{t}=\left\{\begin{array}{lll}
\frac{1}{\overline{h_{m}}} \frac{d \overline{h_{m}}}{d t}, & \text { if } & \frac{d \overline{h_{m}}}{d t}>0 \\
0, & \text { if } & \frac{d \overline{h_{m}}}{d t} \leq 0
\end{array},\right.
$$

and $T_{\text {preceding winter }}^{\prime}$ is the SSTA formed in the preceding winter and preserved at the bottom of the mixed layer. In late fall, when the MLD is deepening, the previous winter's SSTA is mixed into the mixed layer, and thus reemerges (Alexander and Deser 1995). With the 


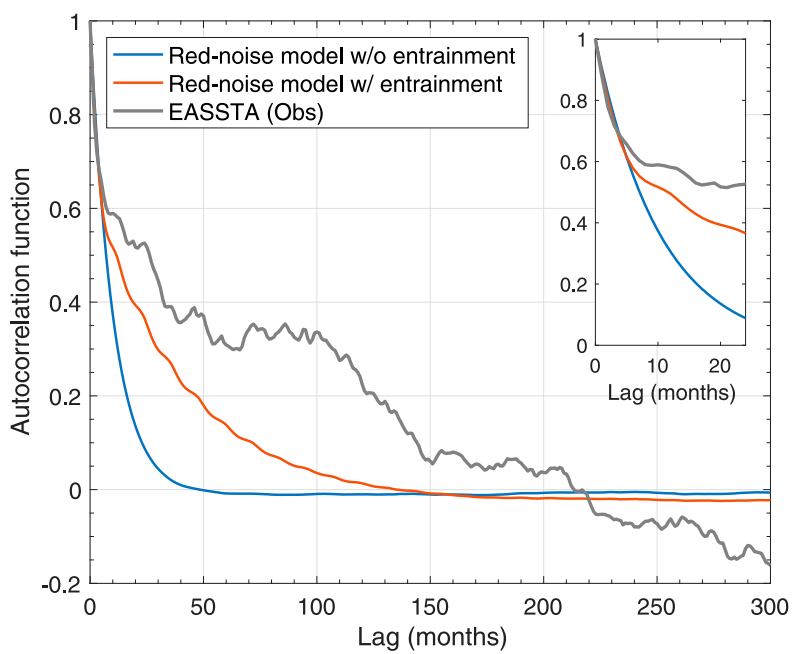

FIG. 10. Autocorrelation function of EASSTA. The gray curve is the autocorrelation function of observed EASSTA (same as the dark blue curve in Fig. 3b). The red and blue curves are, respectively, the EASSTA autocorrelation function simulated by the rednoise model with (corresponding to the orange box in Fig. 8c) and without the reemergence mechanism process (corresponding to the light blue boxes in Figs. 8b,c). The inset is the autocorrelation function for time lags less than 24 months.

reemergence mechanism considered, the idealized model [Eq. (19)] becomes

$$
\begin{aligned}
\frac{\partial T^{\prime}}{\partial t}= & \frac{-T^{\prime}}{\tau}+N\left(0, \sigma_{\text {atmo }}^{2}\right)+N\left(0, \sigma_{\mathrm{MLD}}^{2}\right) \\
& +\gamma_{t} T_{\text {preceding winter }}^{\prime} .
\end{aligned}
$$

The entrainment rate $\gamma_{t}$ is derived from the monthly climatology of MLD in the extratropical North Atlantic. We find $\gamma_{t}=0.425,0.248,0.158$, and $0.05 \mathrm{month}^{-1}$, for the months of October, November, December, and January, respectively; $\gamma_{t}$ is zero for all other months. Including the reemergence process in the red-noise model increases SSTA memory (Fig. 10), consistent with previous studies (Deser et al. 2003; de Coëtlogon and Frankignoul 2003; Buckley et al. 2019). However, the STD of SSTA remains almost unchanged (orange box in Fig. 8c). It is noteworthy that entrainment usually occurs on daily time scales, which cannot be fully resolved by the available observational data. Thus, the contribution of reemergence to EASSTA variability quantified in this study is suggestive rather than conclusive. A more detailed analysis of entrainment will be quantified when higher-resolution MLD data become available.

Finally, we estimate the aerosol forcing on the AMV SSTA STD using model-simulated NASSTA time series. We analyze five CMIP5 models with simulations that isolate the climatic impacts of anthropogenic

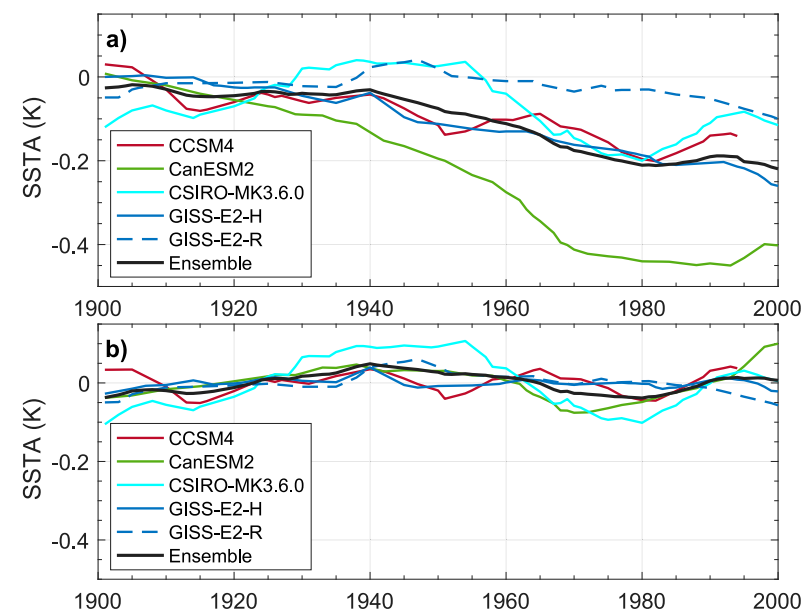

FIG. 11. NASSTA (K) in response to anthropogenic aerosol forcing as simulated by the five CMIP5 models: (a) original SSTA time series and (b) detrended time series. The thick black curves are the ensemble means of the five models.

aerosols. Despite the fact that there is large model uncertainty in the simulated response of anthropogenic aerosols (Fig. 11), we find that regardless of model or data processing methods, the SSTA STD with aerosol forcing cannot match the observed (Fig. 8c). The two data processing methods that we consider are 1) removing a trend to be consistent with our analysis of observational data and 2) considering the nondetrended NASSTA in order to capture the full uncertainty in the modelsimulated response to aerosols (Fig. 11). The SSTA STD ranges from 0.011 to $0.066 \mathrm{~K}$ for the detrended time series and from 0.03 to $0.165 \mathrm{~K}$ for the nondetrended time series (Table 2). By adding the maximum aerosol forcing (nondetrended time series simulated by CanESM2; $0.165 \mathrm{~K}$ ) to the red-noise model, we obtain an SSTA STD in the range of $[0.22,0.28] \mathrm{K}$ (purple box in Fig. 8c). Thus, even the model with the largest response to anthropogenic aerosols still underestimates the observed SSTA variability $(0.36 \mathrm{~K})$ over the extratropical North Atlantic (Fig. 8c). We note that our estimates likely represent the maximum aerosol forcing on SSTA variability for two reasons. First, aerosol forcing cannot easily be separated from the atmospheric heating rate derived from reanalysis datasets. Thus, we may be double-counting the aerosol forcing by adding the CMIP5 model-simulated SSTA variance directly to that estimated by the red-noise model (see section $2 \mathrm{c}$ and purple boxes in Fig. $8 \mathrm{c}$ ). Second, we have considered the situation with the maximum SSTA sensitivity to aerosol radiative forcing in climate models (Table 2 and Fig. 11). It is reasonable to assume that, in reality, the SSTA response to aerosol forcing is weaker than the upper bound of CMIP5 models. Overall, despite the highly uncertain aerosol forcing on North Atlantic 
SSTA, the mismatch between the modeled and observed SSTA STD corroborates our conclusions that emphasize the role of ocean dynamics in forcing SSTA variability.

\section{Conclusions}

This study investigates the role of the ocean in setting the AMV SSTA by using an idealized red-noise model that simulates the ocean mixed layer heat balance. Our analysis suggests that the AMV SSTA persistence results mainly from its extratropical component, where a deep mixed layer and weak damping mechanism make the SSTA more persistent than its tropical counterpart.

The red-noise model forced solely with atmospheric heating substantially underestimates the SSTA STD over the extratropical North Atlantic, suggesting that atmospheric forcing alone is inadequate to generate the observed AMV in this region. Reproducing the observed SSTA STD with atmospheric forcing alone requires a doubling of the atmospheric heating rate or a tripling of the $e$-folding time in the red-noise model. However, because of the inverse relationship between atmospheric heating and the $e$-folding time, these increased parameter values are highly unlikely to occur in the North Atlantic unless there is a drastic shift in the background climate state. Further, we find that adding the contribution of interannual MLD variability, re-emergence, and anthropogenic aerosol forcing does not close the gap between the modeled and observed SSTA STD over the extratropical North Atlantic. In addition, we have tested the results by applying a low-pass filter to the modeled SSTA time series to emphasize the decadal-to-multidecadal variation signals. We found that the gap between the observed EASSTA STD and the atmosphere forced EASSTA STD is larger when a low-pass filter is applied ( $0.07 \mathrm{~K}$ in model simulation vs $0.23 \mathrm{~K}$ in observations) compared to the unfiltered time series. Based on the results of this study, we conclude that 3D ocean dynamics are needed to fully explain the observed AMV SSTA.

The necessity of ocean dynamics based on our results does not nullify the contribution of atmosphere to AMV SSTA (Clement et al. 2015; Cane et al. 2017). We have shown that atmospheric processes are indispensable for forcing the tropical branch of the AMV (Fig. 8a), which is consistent with studies that emphasize the role of the atmosphere (through cloud feedback) in propagating the extratropical SSTA into the tropical North Atlantic and thus creating the spatial coherence of AMV (Bellomo et al. 2016; Brown et al. 2016; Yuan et al. 2016). Our calculations also suggest that atmospheric white noise forcing is nonnegligible for AMV SSTA in the extratropical North Atlantic, as the SSTA STD forced by white noise alone is about half that observed.
Finally, a recent study based on available ocean reanalysis datasets found that $3 \mathrm{D}$ oceanic heat transport is key to interannual-to-decadal SSTA variability in the subpolar North Atlantic (Foukal and Lozier 2018). However, the limitation of ocean observations impedes further analysis of the 3D ocean dynamics important to the AMV SSTA. Considering the significant global and regional climatic impact of the AMV (e.g., Enfield et al. 2001; Hoerling and Kumar 2003; Sutton and Hodson 2005; Zhang and Delworth 2006; Shanahan et al. 2009; Woollings et al. 2012; Tippett et al. 2016), sustained ocean observations that can resolve these dynamics in the extratropical North Atlantic are of high value (Lozier et al. 2017).

Acknowledgments. The authors thank Editors Rong Zhang and Tim DelSole and three anonymous reviewers for their comments and Drs. Ryan Abernathey, Mark Cane, Amy Clement, Nicholas Foukal, Claude Frankignoul, Mingfang Ting, and Rong Zhang for insightful discussions that aided this study. L. Li and M. S. Lozier gratefully acknowledge support from the National Science Foundation (NSF-OCE-17-56223). M. W. Buckley gratefully acknowledges support from the NOAA ESS Program (NA16OAR4310167) and NASA Physical Oceanography Program (NNX17AH49G).

\section{REFERENCES}

Alexander, M. A., and C. Deser, 1995: A mechanism for the recurrence of wintertime mid-latitude SST anomalies. J. Phys. Oceanogr., 25, 122-137, https://doi.org/10.1175/1520-0485(1995) 025<0122:AMFTRO $>2.0 . \mathrm{CO} ; 2$.

Argo, 2019: Argo float data and metadata from Global Data Assembly Centre (Argo GDAC). SEANOE, accessed 2019, https://doi.org/10.17882/42182.

Bellomo, K., A. C. Clement, L. N. Murphy, L. M. Polvani, and M. A. Cane, 2016: New observational evidence for a positive cloud feedback that amplifies the Atlantic Multidecadal Oscillation. Geophys. Res. Lett., 43, 9852-9859, https://doi.org/ 10.1002/2016GL069961.

Bellucci, A., A. Mariotto, and S. Gualdi, 2017: The role of forcings in the twentieth-century North Atlantic multidecadal variability: The 1940-75 North Atlantic cooling case study. J. Climate, 30, 7317-7337, https://doi.org/10.1175/ JCLI-D-16-0301.1.

Booth, B. B. B., N. J. Dunstone, P. R. Halloran, T. Andrews, and N. Bellouin, 2012: Aerosols implicated as a prime driver of twentieth-century North Atlantic climate variability. Nature, 484, 228-232, https://doi.org/10.1038/nature10946.

Brown, P. T., M. S. Lozier, R. Zhang, and W. Li, 2016: The necessity of cloud feedback for a basin-scale Atlantic Multidecadal Oscillation. Geophys. Res. Lett., 43, 3955-3963, https://doi.org/ 10.1002/2016GL068303.

Buckley, M. W., and J. Marshall, 2016: Observations, inferences, and mechanisms of the Atlantic meridional overturning circulation: A review. Rev. Geophys., 54, 5-63, https://doi.org/ 10.1002/2015RG000493. 
R. M. Ponte, G. Forget, and P. Heimbach, 2014: Lowfrequency SST and upper-ocean heat content variability in the North Atlantic. J. Climate, 27, 4996-5018, https://doi.org/ 10.1175/JCLI-D-13-00316.1.

,,--- , and,- 2015 : Determining the origins of advective ocean heat transport convergence variability in the North Atlantic. J. Climate, 28, 3943-3956, https://doi.org/ 10.1175/JCLI-D-14-00579.1.

— North Atlantic sea surface temperature and upper-ocean heat content. J. Climate, 32, 3005-3023, https://doi.org/10.1175/ JCLI-D-18-0509.1.

Cane, M. A., A. C. Clement, L. N. Murphy, and K. Bellomo, 2017: Low-pass filtering, heat flux, and Atlantic multidecadal variability. J. Climate, 30, 7529-7553, https://doi.org/10.1175/ JCLI-D-16-0810.1.

Cayan, D. R., 1992: Latent and sensible heat flux anomalies over the northern oceans: Driving the sea surface temperature. J. Phys. Oceanogr., 22, 859-881, https://doi.org/10.1175/15200485(1992)022<0859:LASHFA >2.0.CO;2.

Clement, A., K. Bellomo, L. N. Murphy, M. A. Cane, T. Mauritsen, G. Rädel, and B. Stevens, 2015: The Atlantic Multidecadal Oscillation without a role for ocean circulation. Science, $\mathbf{3 5 0}$ 320-324, https://doi.org/10.1126/science.aab3980.

Compo, G. P., and Coauthors, 2011: The Twentieth Century Reanalysis project. Quart. J. Roy. Meteor. Soc., 137, 1-28, https://doi.org/10.1002/qj.776.

de Boyer Montégut, C., G. Madec, A. S. Fischer, A. Lazar, and D. Iudicone, 2004: Mixed layer depth over the global ocean: An examination of profile data and a profile-based climatology. J. Geophys. Res., 109, C12003, https://doi.org/10.1029/ 2004JC002378.

de Coëtlogon, G., and C. Frankignoul, 2003: The persistence of winter sea surface temperature in the North Atlantic. J. Climate, 16, 1364-1377, https://doi.org/10.1175/1520-0442-16.9.1364.

Delworth, T., S. Manabe, and R. J. Stoffer, 1993: Interdecadal variations of the thermohaline circulation in a coupled oceanatmosphere model. J. Climate, 6, 1993-2011, https://doi.org/ 10.1175/1520-0442(1993)006<1993:IVOTTC $>2.0$. CO;2.

- F. Zeng, L. Zhang, R. Zhang, G. A. Vecchi, and X. Yang, 2017: The central role of ocean dynamics in connecting the North Atlantic Oscillation to the extratropical component of the Atlantic multidecadal oscillation. J. Climate, 30, 37893805, https://doi.org/10.1175/JCLI-D-16-0358.1.

Deser, C., M. A. Alexander, and M. S. Timlin, 2003: Understanding the persistence of sea surface temperature anomalies in midlatitudes. J. Climate, 16, 57-72, https://doi.org/10.1175/ 1520-0442(2003)016<0057:UTPOSS > 2.0.CO;2.

Drews, A., and R. J. Greatbatch, 2016: Atlantic multidecadal variability in a model with an improved North Atlantic Current. Geophys. Res. Lett., 43, 8199-8206, https://doi.org/10.1002/2016GL069815.

—_, and —_, 2017: Evolution of the Atlantic multidecadal variability in a model with an improved North Atlantic Current. J. Climate, 30, 5491-5512, https://doi.org/10.1175/ JCLI-D-16-0790.1.

Enfield, D. B., A. M. Mestas-Nuñez, and P. J. Trimble, 2001: The Atlantic Multidecadal Oscillation and its relation to rainfall and river flows in the continental U.S. Geophys. Res. Lett., 28, 2077-2080, https://doi.org/10.1029/2000GL012745.

Foukal, N. P., and M. S. Lozier, 2018: Examing the origins of ocean heat content variability in the eastern North Atlantic subpolar gyre. Geophys. Res. Lett., 45, 11275-11283, https://doi.org/ 10.1029/2018GL079122.
Frankignoul, C., and E. Kestenare, 2002: The surface heat flux feedback. Part I: Estimates from observations in the Atlantic and the North Pacific. Climate Dyn., 19, 633-647, https:// doi.org/10.1007/s00382-002-0252-x.

_ A. Czaja, and B. L'Heveder, 1998: Air-sea feedback in the North Atlantic and surface boundary conditions for ocean models. J. Climate, 11, 2310-2324, https://doi.org/10.1175/ 1520-0442(1998)011<2310:ASFITN>2.0.CO;2.

Gastineau, G., and C. Frankignoul, 2015: Influence of the North Atlantic SST variability on the atmospheric circulation during the twentieth century. J. Climate, 28, 1396-1416, https:// doi.org/10.1175/JCLI-D-14-00424.1.

Goldenberg, S. B., C. W. Landsea, A. M. Mestas-Nuñez, and W. M. Gray, 2001: The recent increase in Atlantic hurricane activity: Causes and implications. Science, 293, 474-479, https://doi.org/ 10.1126/science. 1060040.

Good, S. A., M. J. Martin, and N. A. Rayner, 2013: EN4: Quality controlled ocean temperature and salinity profiles and monthly objective analysis with uncertainty estimates. J. Geophys. Res. Oceans, 118, 6704-6716, https://doi.org/10.1002/2013JC009067.

Gulev, S. K., M. Latif, N. Keenlyside, W. Park, and K. P. Koltermann, 2013: North Atlantic Ocean control on surface heat flux on multidecadal timescales. Nature, 499, 464-467, https://doi.org/ 10.1038/nature12268.

Häkkinen, S., P. B. Rhines, and D. L. Worthen, 2011: Atmospheric blocking and Atlantic multidecadal ocean variability. Science, 334, 655-659, https://doi.org/10.1126/science.1205683.

Hanawa, K., and S. Sugimoto, 2004: 'Reemergence' areas of winter sea surface temperature anomalies in the world's oceans. Geophys. Res. Lett., 31, L10303, https://doi.org/10.1029/2004GL019904.

Hasselmann, K., 1976: Stochastic climate models Part I. Theory. Tellus, 28, 473-485, https://doi.org/10.3402/tellusa.v28i6.11316.

Hausmann, U., and A. Czaja, 2012: The observed signature of mesoscale eddies in sea surface temperature and the associated heat transport. Deep-Sea Res. I, 70, 60-72, https://doi.org/ 10.1016/j.dsr.2012.08.005.

Hirahara, S., M. Ishii, and Y. Fukuda, 2014: Centennial-scale sea surface temperature analysis and its uncertainty. J. Climate, 27, 57-75, https://doi.org/10.1175/JCLI-D-12-00837.1.

Hoerling, M., and A. Kumar, 2003: The perfect ocean for drought. Science, 299, 691-694, https://doi.org/10.1126/science.1079053.

Holte, J., L. D. Talley, J. Gilson, and D. Roemmich, 2017: An Argo mixed layer climatology and database. Geophys. Res. Lett., $\mathbf{4 4}$ 5618-5626, https://doi.org/10.1002/2017GL073426.

Huang, B., and Coauthors, 2015: Extended Reconstructed Sea Surface Temperature version 4 (ERSST.v4): Part I. Upgrades and intercomparisons. J. Climate, 28, 911-930, https://doi.org/ 10.1175/JCLI-D-14-00006.1.

Kalnay, E., and Coauthors, 1996: The NCEP/NCAR 40-Year Reanalysis Project. Bull. Amer. Meteor. Soc., 77, 437-471, https://doi.org/10.1175/1520-0477(1996)077<0437:TNYRP> 2.0.CO;2.

Kaplan, A., M. Cane, Y. Kushnir, A. Clement, M. Blumenthal, and B. Rajagopalan, 1998: Analyses of global sea surface temperature 1856-1991. J. Geophys. Res., 103, 18567-18589, https:// doi.org/10.1029/97JC01736.

Kerr, K. A., 2000: A North Atlantic climate pacemaker for the centuries. Science, 288, 1984-1985, https://doi.org/10.1126/ science.288.5473.1984.

Kim, W. M., S. G. Yeager, and G. Danabasoglu, 2018: Key role of internal ocean dynamics in Atlantic multidecadal variability during the last half century. Geophys. Res. Lett., 45, 13449 13 457, https://doi.org/10.1029/2018GL080474. 
Latif, M., and N. S. Keenlyside, 2011: A perspective on decadal climate variability and predictability. Deep-Sea Res. II, 58, 1880-1894, https://doi.org/10.1016/j.dsr2.2010.10.066.

Liu, W., and Coauthors, 2015: Extended Reconstructed Sea Surface Temperature version 4 (ERSST.v4): Part II. Parametric and structural uncertainty estimations. J. Climate, 28, 931-951, https://doi.org/10.1175/JCLI-D-14-00007.1.

Lozier, M. S., and Coauthors, 2017: Overturning in the Subpolar North Atlantic Program: A new international ocean observing system. Bull. Amer. Meteor. Soc., 98, 737-752, https://doi.org/ 10.1175/BAMS-D-16-0057.1.

McCabe, G. J., M. A. Palecki, and J. L. Betancourt, 2004: Pacific and Atlantic Ocean influences on multi-decadal drought frequency in the United States. Proc. Natl. Acad. Sci. USA, 101, 4136-4141, https://doi.org/10.1073/pnas.0306738101.

McCarthy, G. D., I. D. Haigh, J. J. M. Hirschi, J. P. Grist, and D. A. Smeed, 2015: Ocean impact on decadal Atlantic climate variability revealed by sea-level observations. Nature, 521, 508510, https://doi.org/10.1038/nature14491.

O'Reilly, C. H., M. Huber, T. Woollings, and L. Zanna, 2016: The signature of low-frequency oceanic forcing in the Atlantic Multidecadal Oscillation. Geophys. Res. Lett., 43, 2810-2818, https://doi.org/10.1002/2016GL067925.

_, T. Woollings, and L. Zanna, 2017: The dynamical influence of the Atlantic multidecadal oscillation on continental climate. J. Climate, 30, 7213-7230, https://doi.org/10.1175/JCLI-D-16-0345.1.

Otterå, O. H., M. Bentsen, H. Drange, and L. Suo, 2010: External forcing as a metronome for Atlantic multidecadal variability. Nat. Geosci., 3, 688-694, https://doi.org/10.1038/ngeo955.

Rayner, N. A., D. E. Parker, E. B. Horton, C. K. Folland, L. V. Alexander, D. P. Rowell, E. C. Kent, and A. Kaplan, 2003: Global analyses of sea surface temperature, sea ice, and night marine air temperature since the late nineteenth century. J. Geophys. Res., 108, 4407, https://doi.org/10.1029/ 2002JD002670.

Ruprich-Robert, Y., and C. Cassou, 2015: Combined influences of seasonal East Atlantic pattern and North Atlantic Oscillation to excite Atlantic Multidecadal Variability in a climate model. Climate Dyn., 44, 229-253, https://doi.org/10.1007/s00382-0142176-7.

Schlesinger, M.-E., and N. Ramankutty, 1994: An oscillation in the global climate system of period $65-70$ years. Nature, 367, 723 726, https://doi.org/10.1038/367723a0.

Seager, R., R. Murtugudde, N. Naik, A. Clement, N. Gordon, and J. Miller, 2003: Air-sea interaction and the seasonal cycle of the subtropical anticyclones. J. Climate, 16, 1948-1966, https:// doi.org/10.1175/1520-0442(2003)016<1948:AIATSC > 2.0.CO;2.

Shanahan, T. M., and Coauthors, 2009: Atlantic forcing of persistent drought in West Africa. Science, 324, 377-380, https:// doi.org/10.1126/science.1166352.

Stephens, G. L., and Coauthors, 2012: An update on Earth's energy balance in light of the latest global observations. Nat. Geosci., 5, 691-696, https://doi.org/10.1038/ngeo1580.

Sutton, R. T., and D. L. R. Hodson, 2005: Atlantic Ocean forcing of North American and European summer climate. Science, 309, 115-118, https://doi.org/10.1126/science.1109496.

, G. D. McCarthy, J. Robson, B. Sinha, A. T. Archibald, and L. J. Gray, 2018: Atlantic multi-decadal variability and UK ACSIS programme. Bull. Amer. Meteor. Soc., 99, 415-425, https://doi.org/10.1175/BAMS-D-16-0266.1.
Taylor, K. E., R. J. Stouffer, and G. A. Meehl, 2012: An overview of CMIP5 and the experiment design. Bull. Amer. Meteor. Soc., 93, 485-498, https://doi.org/10.1175/BAMS-D-11-00094.1.

Timmermann, A., M. Latif, R. Voss, and A. Grötzner, 1998: Northern Hemispheric interdecadal variability: A coupled airsea mode. J. Climate, 11, 1906-1931, https://doi.org/10.1175/ 1520-0442-11.8.1906.

Ting, M., Y. Kushnir, R. Seager, and C. Li, 2009: Forced and internal twentieth-century SST trends in the North Atlantic. J. Climate, 22, 1469-1481, https://doi.org/10.1175/2008JCLI2561.1.

,,--- , and -2011 : Robust features of Atlantic multidecadal variability and its climate impacts. Geophys. Res. Lett., 38, L17705, https://doi.org/10.1029/2011GL048712.

Tippett, M. K., C. Lepore, and J. E. Cohen, 2016: More tornadoes in the most extreme U.S. tornado outbreaks. Science, 354, 1419-1423, https://doi.org/10.1126/science.aah7393.

Trenberth, K. E., and D. J. Shea, 2006: Atlantic hurricanes and natural variability in 2005. Geophys. Res. Lett., 33, L12704, https://doi.org/10.1029/2006GL026894.

Wills, R. C. J., K. C. Armour, D. S. Battisti, and D. L. Hartmann, 2019: Ocean-atmosphere dynamical coupling fundamental to the Atlantic multidecadal oscillation. J. Climate, 32, 251-272, https://doi.org/10.1175/JCLI-D-18-0269.1.

Woollings, T., J. M. Gregory, J. G. Pinto, M. Reyers, and D. J. Brayshaw, 2012: Response of the North Atlantic storm track to climate change shaped by ocean-atmosphere coupling. Nat. Geosci., 5, 313-317, https://doi.org/10.1038/ngeo1438.

Worley, S. J., S. D. Woodruff, R. W. Reynolds, S. J. Lubker, and N. Lott, 2005: ICOADS release 2.1 data and products. Int. J. Climatol., 25, 823-842, https://doi.org/10.1002/joc.1166.

Xie, S.-P., and S. G. H. Philander, 1994: A coupled ocean-atmosphere model of relevance to the ITCZ in the eastern Pacific. Tellus, 46A, 340-350, https://doi.org/10.3402/tellusa.v46i4.15484.

Yuan, T., L. Oreopoulos, M. Zelinka, H. Yu, J. R. Norris, M. Chin, S. Platnick, K. Meyer, 2016: Positive low cloud and dust feedbacks amplify tropical North Atlantic Multidecadal Oscillation. Geophys. Res. Lett., 43, 1349-1356, https://doi.org/10.1002/ 2016 GL067679.

Zhang, R., 2017: On the persistence and coherence of subpolar sea surface temperature and salinity anomalies associated with the Atlantic multidecadal variability. Geophys. Res. Lett., 44, 7865-7875, https://doi.org/10.1002/2017GL074342.

, and T. L. Delworth, 2006: Impact of Atlantic multidecadal oscillations in India/Sahel rainfall and Atlantic hurricanes. Geophys. Res. Lett., 33, L17712, https://doi.org/10.1029/ 2006 GL026267.

, R. Sutton, G. Danabasoglu, T. L. Delworth, W. M. Kim, J. Robson, and S. G. Yeager, 2016: Comment on "The Atlantic Multidecadal Oscillation without a role for ocean circulation." Science, 352, 1527, https://doi.org/10.1126/science.aaf1660.

_, ——, ——, Y.-O. Kwon, R. Marsh, S. G. Yeager, D. E. Amrhein, and C. M. Little, 2019: A review of the role of the Atlantic meridional overturning circulation in Atlantic Multidecadal Variability and associated climate impacts. Rev. Geophys., 57, 316-375, https://doi.org/10.1029/2019RG000644.

Zhao, J., A. Bower, J. Yang, X. Lin, and N. P. Holliday, 2018: Meridional heat transport variability induced by mesoscale processes in the subpolar North Atlantic. Nat. Commun., 9, 1124, https://doi.org/10.1038/s41467-018-03134-x. 